\title{
Cucurbitacin $B$ and cancer intervention: Chemistry, biology and mechanisms (Review)
}

\author{
SUKANT GARG ${ }^{1,2}$, SUNIL C. KAUL ${ }^{1}$ and RENU WADHWA ${ }^{1,2}$ \\ ${ }^{1}$ Drug Discovery and Assets Innovation Lab, DBT-AIST International Laboratory for Advanced Biomedicine \\ (DAILAB), National Institute of Advanced Industrial Science and Technology (AIST), Tsukuba 305-8565; \\ ${ }^{2}$ School of Integrative and Global Majors, University of Tsukuba, Tsukuba 305-8577, Japan
}

Received August 8, 2017; Accepted October 23, 2017

DOI: $10.3892 /$ ijo. 2017.4203

\begin{abstract}
Cancer is one of the most important healthcare matters, with the worst prognosis but the best possibilities for scientific development. It is likely to increase in the future and cause global havoc designating it as an epidemic. Cancer development requires urgent intervention. Past few decades have witnessed extensive research to challenge carcinogenesis. Treatment involving synthetic discipline is often associated with severe adverse effects, or even worsened prognosis. Accordingly, newer economic and patient friendly molecules are warranted. Many natural substances have proved their potential so far. Cucurbitacin B against cancer and other diseases has achieved towering popularity among the researchers around the world, as detailed in the below sections with summarized tables. In line with the fascinating role of cucurbitacin B against various types of cancers, through various molecular signaling pathways, it is justifiable to propose cucurbitacin B as a mainline chemotherapy before the onset and after the diagnosis of cancer.
\end{abstract}

\section{Contents}

1. Cancer

2. Cucurbitacin $B$

3. Cucurbitacin B - sources

4. Cucurbitacin B - anticancer activity

5. Cucurbitacin B - as combination therapy

6. Cucurbitacin B - other biological systems

7. Cucurbitacin B - toxicity

8. Cucurbitacin B - biological supply chain and future scope

9. Summary

Correspondence to: Dr Renu Wadhwa, Drug Discovery and Assets Innovation Lab, DBT-AIST International Laboratory for Advanced Biomedicine (DAILAB), National Institute of Advanced Industrial Science and Technology (AIST), Tsukuba 305-8565, Japan

E-mail: renu-wadhwa@aist.go.jp

Key words: cancer, cucurbitacin $\mathrm{B}$, anticancer molecule, natural chemotherapy mechanism

\section{Cancer}

Cancer is a syndrome of diseases wherein the cells upon aberrant mutations/environmental stresses witness either the activation of proto-oncogenes or the suppression of tumor suppressor proteins. Resultantly, they undergo uncontrolled infinite replication, lose their functional characteristics and exploit their physiological neighbors for nutrients and space. The process is often accompanied with malignant transformation and metastatic spread, EMT (1), especially when the availability of resources at a particular cancer niche shortens. Various mechanisms like autocrine and endocrine regulation of growth factors, platelet adhesion, quiescence, cytoskeleton rearrangements, cancer cell differentiation, micrometastasis, EMT, angiogenesis and niche formation determine the outcome. WHO data states that the global cancer burden is likely to rise to 22 million by 2030 (2), due to a variety of homeostatic insults. Cancer cells operate via various molecular mechanisms, popularly categorized as the cell signaling pathways. We provide an outline of the major tumor suppressor and oncogenic pathways, which regulate the process of human carcinogenesis.

Tumor suppressor p53 protein (Fig. 1) is known as the guardian of the genome (3-5). External or internal cellular injury to a normal cell activates the p53 tumor suppressor pathway. It directs the cell into growth arrest and apoptotic state via activation of several downstream effectors including growth arrest (p21 ${ }^{\mathrm{WAF} 1}$ and others) and apoptosis (BAX, PUMA and others) inducing proteins. Retinoblastoma (RB) protein (Fig. 1) is coded by RB1 tumor suppressor gene (6-9). At the $\mathrm{G}_{1}-\mathrm{S}$ checkpoint, escalated cyclin D binds with CDK4 leading to $\mathrm{pRB}$ phosphorylation, abrogation of $\mathrm{pRB}-\mathrm{E} 2 \mathrm{~F}$ complexes and free E2F, which translocates to nucleus and activates genetic transcription via polymerase secretion, which is crucial for proliferation.

Wnt protein interacts with frizzled receptor extracellularly and deactivates $\beta$-catenin-destruction complex, which is made up of GSK3, Axin, CSK1 $\alpha$, PP2A and APC, coded by their respective genes (10). The complex binds to $\beta$-catenin present in the cytoplasm and degrades it via phosphorylationubiquitination-proteasomal degradation. Mutations in any of them (ultimately resulting into cancer), most frequently in APC, result in faulty complex structure, which fails to bind 


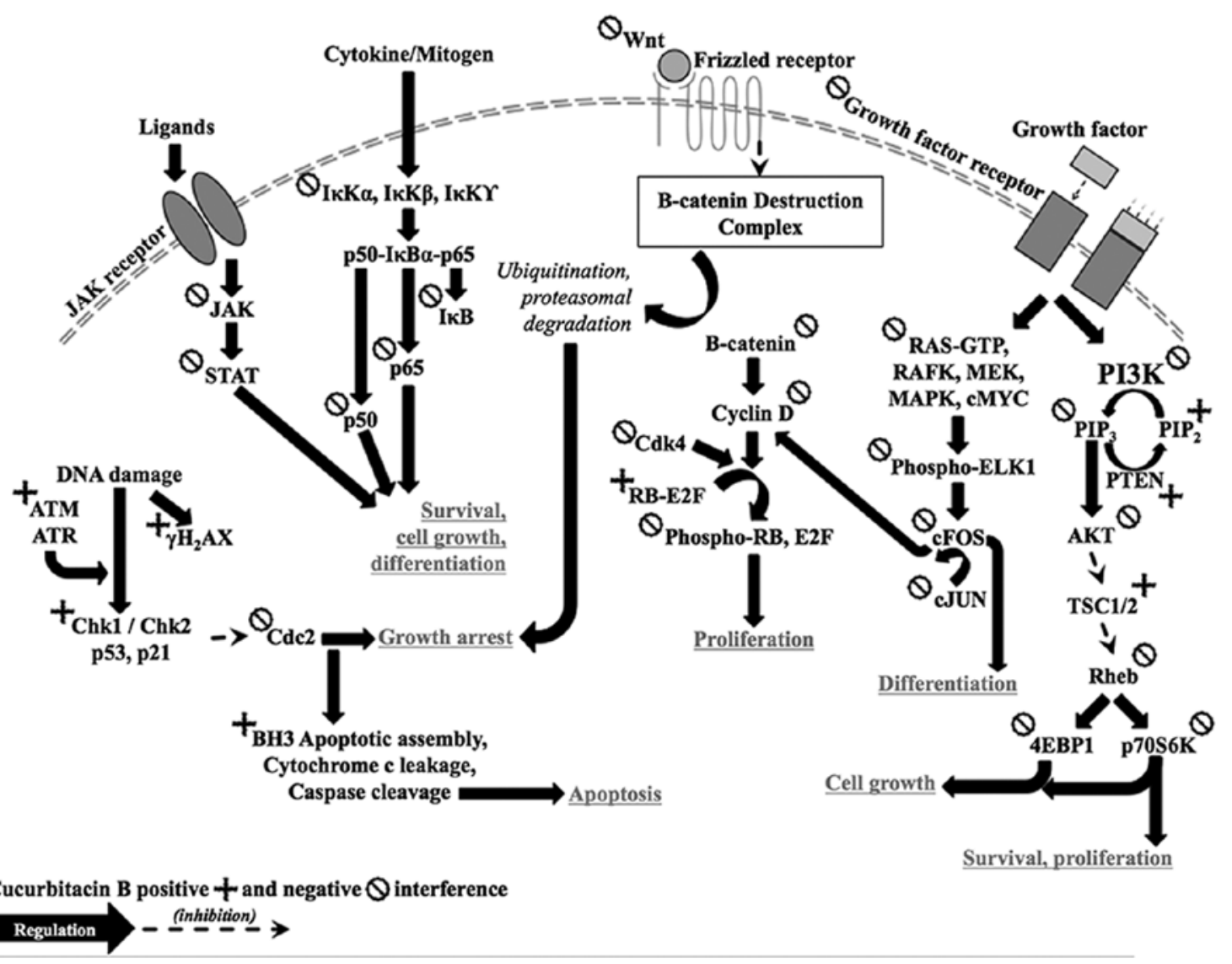

Figure 1. Major cell signaling pathways contributing to cancer and modulation by cucurbitacin B. Upregulation (+) and downregulation $(\theta)$ of protein expression.

to and degrade $\beta$-catenin. Excess $\beta$-catenin translocates to the nucleus, binds with galectin-3, interacts with T-cell transcription and lymphoid enhancing transcription factors, and promotes genes, which code for cyclin D protein essential for $\mathrm{G}_{1} / \mathrm{S}$ cell cycle transition. STAT3 is a latent transcriptional factor in the cytoplasm, which is regulated by JAK phosphorylation (Fig. 1) (11-18). It directly or indirectly upregulates genes associated with tumor proliferation and survival, and constitutes an important intracellular signal transduction pathway in cancer, which regulates cancer cell growth and differentiation. Inactivation or de-phosphorylation of the protein forces cells to undergo growth arrest and apoptosis.

Cancer tissue is fast growing and evading, central mass of which often suffers hypoxia. Emergency mechanisms such as HIF signaling get activated, which trigger angiogenesis, metastatic spread of disease and resistance to chemotherapy. HIF-1 monomer is continuously transcribed and translated, and degraded via ubiquitin mediated proteasomal degradation under normoxic conditions. In hypoxic condition, this degradation is downregulated, resulting into accumulation of monomer. Accumulated monomers translocate to the nucleus and dimerize with HIF-1 $\beta$ to form a complex, which modulates transcription and translation of the target genes. NF- $\kappa \mathrm{B}$ proteins function as dimeric transcription factors and regulate the expression of genes influencing immunological, stress and inflammatory response (19). NF- $\kappa \mathrm{B}$ pathway proteins are normally bound to $\mathrm{I} \kappa \mathrm{B}$ and remain in an inactive state. Pro-inflammatory cytokines and other mitogens activate IKK complex (IKK $\beta$-IKK $\alpha$-NEMO), which phosphorylates I $\mathrm{B}$ proteins for its ubiquitination and proteasomal degradation. Free and active NF- $\kappa \mathrm{B}$ upon further phosphorylation, acetylation and glycosylation, translocate to nucleus to induce target gene expression.

Activated dimer of GFR phosphorylates RAS-GDP complex to RAF-GTP, which via series of downstream phosphorylation activates RAF kinase, MEK, MAP kinase and cMYC in cytosol and ELK1 in the nucleus (Fig. 1) (20). ELK1 further activates cFOS transcription, which dimerize with cJUN. Activated cMYC and cJUN-cFOS complex triggers subsequent transcription, which are essential for DNA replication, such as cyclin D. Receptor tyrosine kinase activates PI3K, a complex of p85 and p110 proteins (21). Activated PI3K phosphorylates PIP2 into PIP3, which via PDK1 activation phosphorylates AKT. After downstream signaling involving TSC1/2, Rheb and mTORC1 it activates p70S6K and 4EBP1, which via estrogen receptor further translates to cell survival, growth, proliferation, differentiation, migration and metabolism. Telomeres are specialized chromosome ends in the cells consisting of tightly held and repetitive (10-15 kb) TTAGGG sequence, and protein caps, which protect chromosomes from terminal fusion $(22,23)$. Every time a normal cell divides a small portion of the telomeric end gets eroded of $\sim 50-200$ base pairs until the bare chromosomal ends are left. At this stage, cell enters an irreversible and non-proliferative phase called replicative senescence. Most cancer cells acquire the ability to synthesize enzyme telomerase, which helps to regenerate telomeric ends. Autophagy is a conservation-indicated destructive process, wherein the non-functional or stressed 

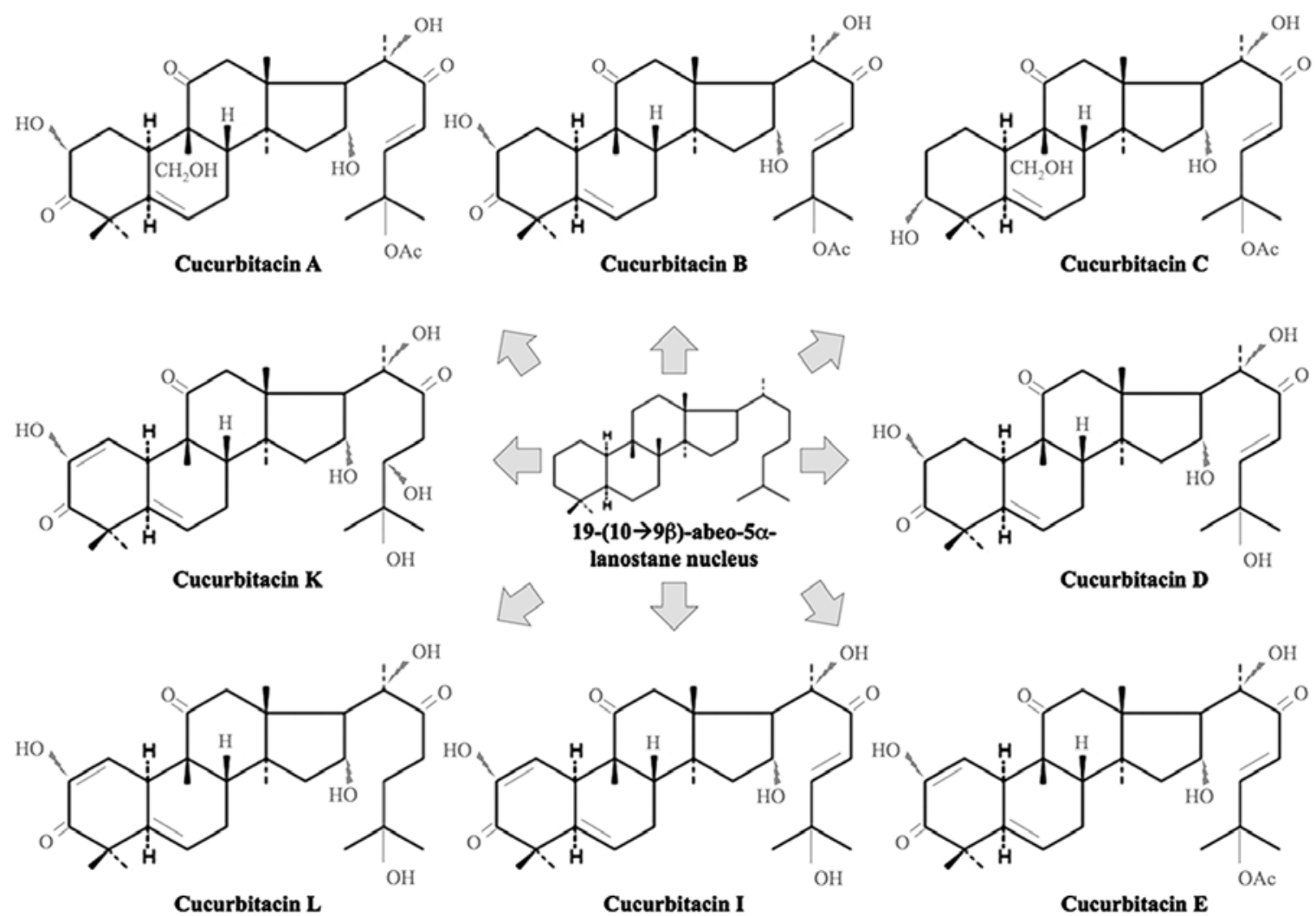

Figure 2. Two-dimensional chemical molecular structures of cucurbitacins and cucurbitacin B and differences between various subtypes (141).

cytoplasmic organelles and other constituents are delivered to lysosomes (24). Lysosome engulfs and digests the material, and release energy and other important elements, which may be utilized in cellular metabolism. It is frequently found to take place as a response to cellular stress, but is skeptical as it may be either protective or discretely destructive. It is characterized by the appearance of large cytoplasmic vacuoles or vesicles with upregulation of ATG family proteins viz., LC3II/I, ULK1/2 and Beclin1. Stress stimuli, nutritional imbalance, hypoxia and other chemical mediators like ROS and insults to intracellular homeostasis may lead to induction of autophagy response.

Prevention of production of ROS or catabolic destruction of ROS is explicitly defined as the antioxidant mechanism. ROS are charged super-ions, continually generated and released in the cells, presenting with vacuolization in cytosol and reaction with biomolecules like cell organelles and genetic material to generate peroxides and malondehyde. These alter membrane potential and signal transduction, and may induce cell offing mechanisms like necrosis, apoptosis and autophagy. ROS generation increases as a result of environment insults like pollution, radiation and infestation. Prevention and control of cancer is one of the most expensive and least prolific healthcare investments, on top of which it is also burdened with toxic adverse effects associated with chemotherapy and radiotherapy. Use of natural medicines could not only lower the expenditure towards the disease extensively, but may also bring down the adverse effects rate in clinical patients. Holistic approach (consumption of natural and related molecules in the ratio prepared by nature) for the treatment of cancer, could be adopted. Kaefer and Milner (25) enumerated a list of benefits if the treatment of the disease is mainly herbal, and their probable role in cancer. Many biologically active molecules from the herbal sources have been identified in the last few decades, which in experiment have potential to prevent the disease, control its growth, and possibly eradicated it completely. Cucurbitacin B is one of the most extensively studied natural bioactives.

\section{Cucurbitacin B}

Cucurbitacins are chemically characterized by tetracyclic cucurbitane (triterpene hydrocarbon) nucleus skeleton $19-(10 \rightarrow 9 \beta)$-abeo-5 $\alpha$-lanostane base, varied by the positional substitution of an oxygen atom (Fig. 2) $(8,26)$. There are mainly 40 known species of cucurbitacins and their derivatives, divided into 12 groups namely A, B, C, D, E, I, H, Q, R, dihydrocucurbitacin $B$ (27). These are usually crystalline in nature, purgative, hydrophobic and easily soluble in organic solvents with absorption maxima for ultraviolet light ranging from 228 to $234 \mathrm{~nm}$, having exceptions such as cucurbitacin $\mathrm{H}$, which is usually an amorphous solid. Various studies have been conducted to examine the effects of these compounds in various cell lines in vitro and in vivo against different cancer subtypes (A/B/E/D/I/Q, lung; B/E/D/I/dihydrocucurbitacin B, breast, neurological, colon and hepatocellular; E/I, prostate; E, ovarian; D/dihydrocucurbitacin B, leukemia; D, lymphoma; $\mathrm{Q}$, murine). Cucurbitacin $\mathrm{B}$ has been one of the most explored for its role in biological systems. Cucurbitacin $\mathrm{B}\left(\mathrm{C}_{32} \mathrm{H}_{46} \mathrm{O}_{8}\right.$, molecular weight $558.712 \mathrm{~g} / \mathrm{mol}, 19-(10 \rightarrow 9 \beta)$-abeo-10-lanost5 -ene triterpene), found in the plants of cucurbitaceae and other plant families like Brassicaceae, is classified as a steroid with peculiar bitter taste and cytotoxic properties. Its bitterness 
Table I. Potency of cucurbitacin B against various diseases.

\begin{tabular}{|c|c|c|c|c|}
\hline Year & Source & Presenting condition & Activity explored & Refs. \\
\hline 1988 & Ecballium elaterium & Inflammation & Vascular permeability & $(42)$ \\
\hline 1989 & Citrullus colocynthis & - & - & (33) \\
\hline 2000 & Casearia arborea & Brain and skin cancer & Cytotoxicity & (37) \\
\hline 2001 & Licania intrapetiolaris & Oral epidermoid cancer & Cytotoxicity & $(36)$ \\
\hline 1999 & Leukopaxillus gentianeus & Multiple cancers & Cytotoxicity & $(28)$ \\
\hline 2004 & Begonia nantoensis & Multiple cancers & Cytotoxicity & $(41)$ \\
\hline 2006 & Cayaponia racemosa & - & - & $(32)$ \\
\hline 2006 & Leucopaxillus gentianeus & Lung cancer & Cytotoxicity & $(30)$ \\
\hline 2007 & Citrullus colocynthis & Breast cancer & Cytotoxicity & $(45)$ \\
\hline 2008 & Trichosanthes cucumerina & Multiple cancers & Cytotoxicity & $(81)$ \\
\hline 2009 & Cucumis melo & Multiple cancers & Cytotoxicity & (39) \\
\hline 2010 & Trichosanthes cucumerina & Breast cancer & Cytotoxicity & $(47)$ \\
\hline 2010 & Trichosanthes kirilowii & Liver cancer & Cytotoxicity & $(40)$ \\
\hline 2011 & Cucumis prophetarum & Embryonic cancer & Cytotoxicity & $(38)$ \\
\hline 2012 & Trichosanthes cucumerina & Breast cancer & Cytotoxicity & $(10)$ \\
\hline 2012 & Trichosanthes cucumerina & Breast cancer & Cytotoxicity & $(49)$ \\
\hline 2012 & Luffa operculata & Lung cancer & - & $(60)$ \\
\hline 2013 & Trichosanthes cucumerina & Breast cancer & Cytotoxicity & $(50)$ \\
\hline 2014 & Cucurbita pepo & Inflammation & ROS scavenging and COX $-1 / 2$ inhibition & $(43)$ \\
\hline 2014 & Lagenaria siceraria & & & \\
\hline 2014 & Luffa cylindrical & & & \\
\hline 2014 & Trichosanthes kirilowii & Multiple cancers & Cytotoxicity & $(92)$ \\
\hline 2015 & Luffa graveolense & Lung cancer & Cytotoxicity & (64) \\
\hline 2015 & Ecballium elaterium & Liver inujry & Hepatoprotection & $(126)$ \\
\hline 2016 & Helicteres angustifolia & Bone cancer & Cytotoxicity & $(35)$ \\
\hline 2016 & Luffa graveolense & Breast cancer & Cytotoxicity & $(59)$ \\
\hline 2016 & Wilbrandia ebracteata & Lung cancer & Cytotoxicity & $(65)$ \\
\hline 2016 & Luffa graveolense & Lung cancer & Cytotoxicity & $(66)$ \\
\hline 2017 & Ecballium elaterium & Multiple cancers & Cytotoxicity & (76) \\
\hline
\end{tabular}

could offer it protection against predators and parasites (28). It has previously been reported to be effective against various illnesses notably generalized inflammation and algesia, carbon chloride-induced hepatotoxicity and profound cholestasis, CD18-mediated disorders, infestation of insects, cell adhesion and leukemic disorders, immune mediated and angiogenic disorders (29-31). Dantas et al (32) analyzed few derivatives of cucurbitacin obtained from the seeds of Cayaponia racemosa for cytotoxic potential. Nearly all were lethal to brine shrimp and inhibited cancer cell proliferation. However, their toxicity did not reach the order to inhibit the biological development of sea urchin or mouse erythrocytic lysis. The authors credited this to the chemical structure of cucurbitacins, and postulated that such differences in toxicity profile could be attributed to the position of carbonyl group at carbon-11 and absence of a double bond between carbon-23 and carbon-24. In another study, authors isolated a chemical substitute of cucurbitacin B from the fruiting bodies of mushroom Leucopaxillus gentianeus, which differed from cucurbitacin B in lacking an oxygen substituent at carbon-16, and screened for antitumor toxicity with respect to chemical structure variation (30). This minute substitution might be responsible for its significant ( 6-fold) antitumor profile. It has high affinity for glycosides and, not rare to find cucurbitacin B in a naturally bound form. Hatam et al (33) isolated and performed NMR studies on cucurbitacin glycosides derived from the fruit of Citrullus colocynthis L. Schrad. Cucurbitacin B showed strong affinity to human serum albumin via hydrophobic and electrostatic forces and increased the binding of ibuprofen to albumin (34). This indicated the catalytic role of cucurbitacin B in NSAIDspharmacokinetics.

\section{Cucurbitacin B - sources}

Cucurbitacin B has been extracted from plants of various families and genera around the world for research purpose (compiled in Table I). We examined the effect of cucurbitacin B, derived from Helicteres angustifolia (35), on a variety of cancer and normal cells and discovered its cytotoxic potential in bone osteosarcoma cells at nanomolar doses. Cucurbitacin B fractionated from the methanolic extract of Licaniaintra petiolaris was analyzed for toxicity via kenacid acid cytotoxicity assay (36) and, caused, at the dose $<0.01 \mu \mathrm{g} / \mathrm{ml},>50 \%$ cell death in human oral epidermoid carcinoma cells. Cucurbitacin B obtained in both pure and glycoside form from the fractionation from root extract of Casearia arborea showed potent cytotoxicity against 


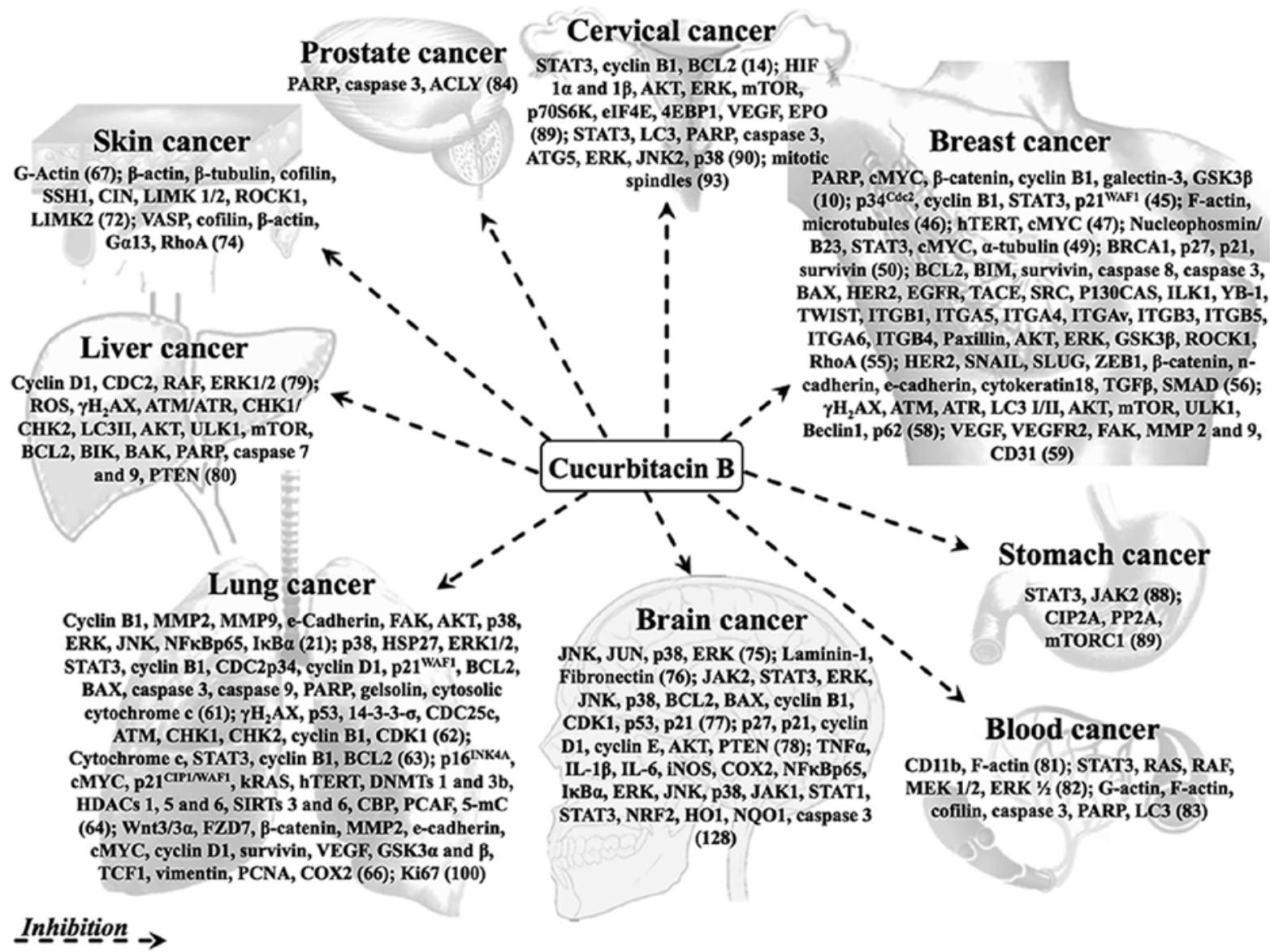

Figure 3. Summary of anticancer molecular mechanisms (site-wise) by cucurbitacin B. All stated proteins are either upregulated or downregulated, contributing to the inhibition of cancer development.

gliosarcoma and melanoma cell lines (37); from the chloroform-methanol extracts of Cucumis prophetarum it showed cytotoxicity against tumor derived and virally transformed mouse cancer cells (38); from the fruiting bodies of the fungal mushroom Leucopaxillus gentianeus it showed very strong cytotoxicity against NSCLC, RCC, HCC and HER2//ER ${ }^{+}$ breast carcinoma cells (28); from the stems of Cucumis melo it showed significant cytotoxicity against NSCLC and HCC in vitro via activation of phospho-STAT3 (39); from the fruiting bodies of the fungal mushroom Leucopaxillus gentianeus it showed cytotoxicity against NSCLC, RCC, HCC and HER2 -1 $\mathrm{ER}^{+}$breast carcinoma cells (28); and from the methanol extract of Trichosanthes kirilowii Cucurbitacin B and its close relatives demonstrated potent anticancer activities mediated through HIF- $1 \alpha$ and NF- $\kappa B$ suppression (40). From the air-dried rhizomes of Begonia nantoensis it not only showed cytotoxicity against NSCLC, HER2 $-/ \mathrm{ER}^{+}$breast carcinoma, gastric adenocarcinoma and non-neoplastic nasopharyngeal epithelial cell carcinoma cells, but also inhibited HIV replication in human T-lymphocytes, flaunting its potential as an anti-viral molecule (41).

Many studies have shed light on other medicinal properties of cucurbitacin B. Yesilada et al (42) showed potent anti-inflammatory activity in a fraction from the freeze-dried fruit juice of squirting cucumber Ecballium elaterium L. Rich. Rawat et al (43) demonstrated the anti-oxidant and anti-inflammatory potential of extracts of cucurbits Lagenaria siceraria, Cucurbita pepo and Luffa cylindrical. Overall, in last 50 years, cucurbitacin B has been shown to possess therapeutic value for ailments such as cancer, HIV-AIDS and inflammatory disorders. Indeed, methods for preparing cucurbitacin with longer shelf life have been developed (44). More recently, several studies, using in vitro and in vivo approaches, have reported its mechanism of action.

\section{Cucurbitacin B - anticancer activity}

Many researchers around the world have based their research questions on the activity of cucurbitacin B in cancer cells (compiled in Table II). Cucurbitacin B has been shown to possess strong anticancer activity in a variety of cancers in vitro and in vivo (Fig. 3).

Breast cancer. Tannin-Spitz et al (45) isolated cucurbitacin glycosides from the leaves of Citrullus colocynthis and found that the combination (cucurbitacin B/E glycosides 1:1) inhibited the growth of breast cancer cells in a dose- and time-dependent fashion, and forced the cells into $\mathrm{G}_{2} / \mathrm{M}$ phase cell cycle arrest furthering into apoptosis. Growth arrest was elucidated by the downregulation of $\mathrm{p} 34^{\mathrm{Cdc}} / \mathrm{cyclin} \mathrm{B} 1$ protein complex and upregulation of phospho-STAT3 and p21 $1^{\mathrm{WAF} 1}$. Breast cancer cells treated with the combination of cucurbitacin B and glycosides showed remarkable annular appearance representative of actin filament disruption. This led to ER status-independent inhibition 


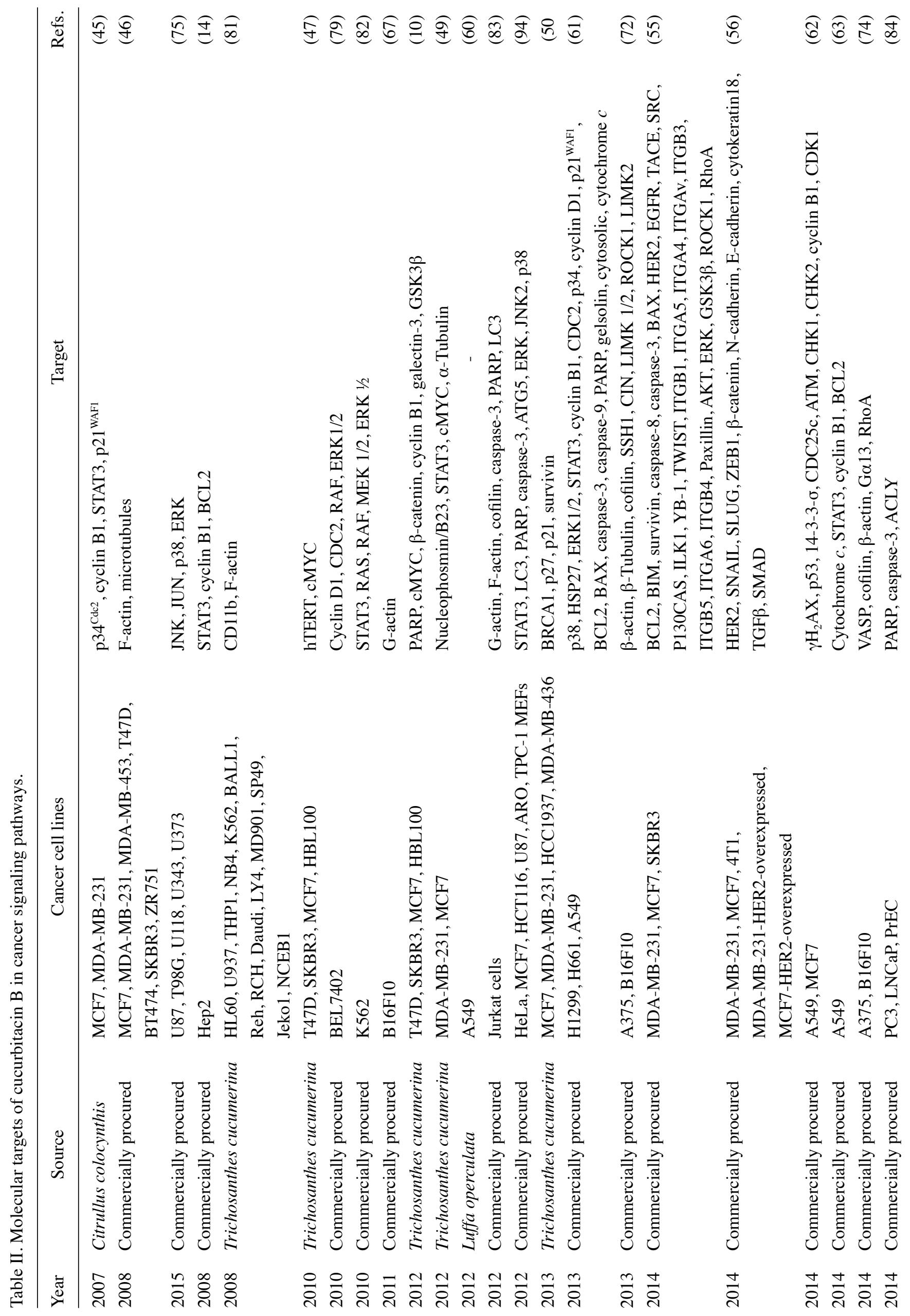




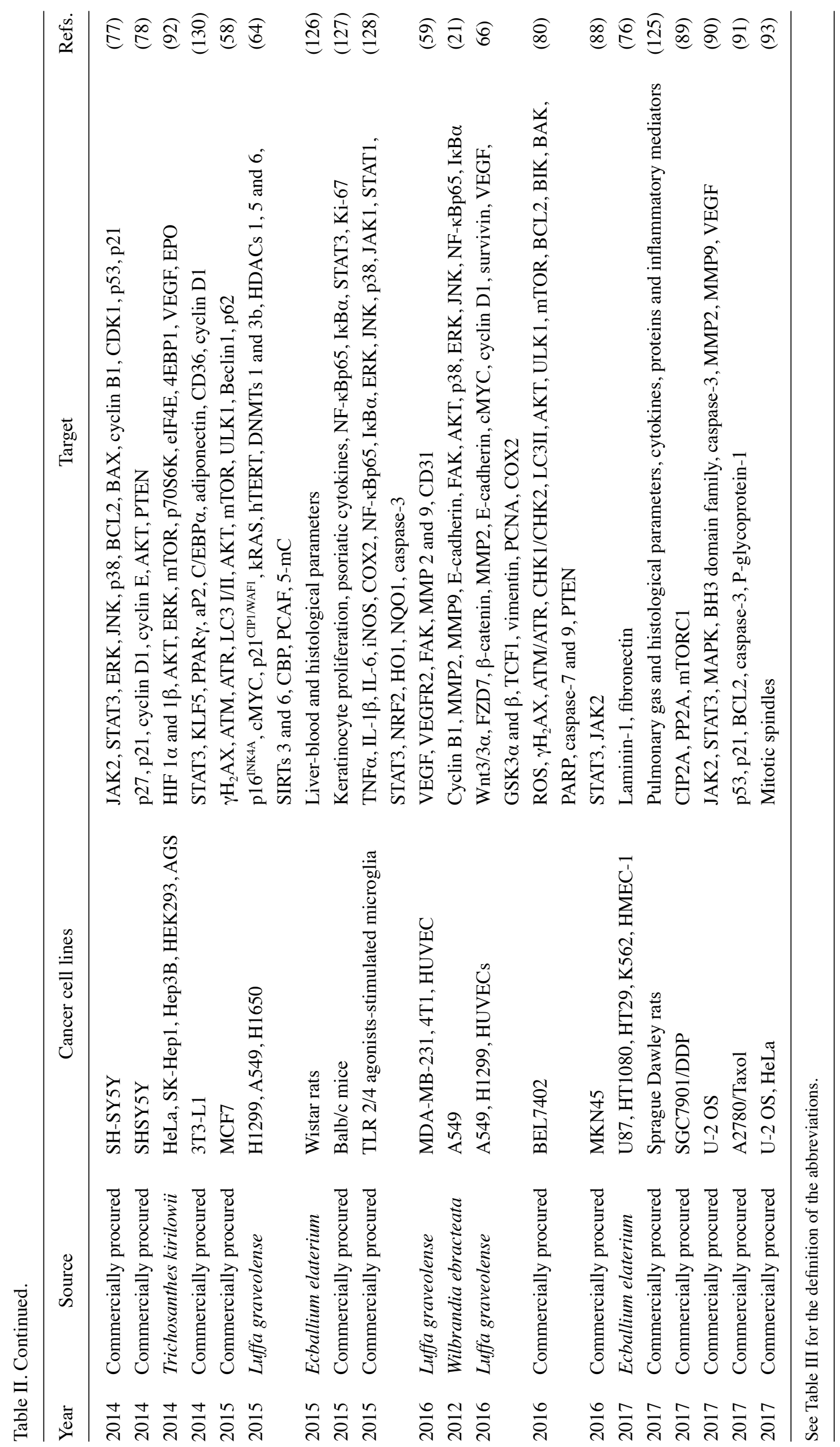


of PKB protein phosphorylation and reduction in the expression of survivin, contributing to apoptosis. Wakimoto et al (46) confirmed that cucurbitacin B induced dose-dependent disruption of actin microtubules and filaments to illustrate rapid morphological changes in breast cancer cells, as soon as 15-20 min after exposure to the compound. These were due to the disruption of F-actin within 3-5 min after exposure, followed by disruption of microtubules over 15-20 min. These findings were verified using nude mice, in which tri-weekly orthotopic $1 \mathrm{mg} / \mathrm{kg}$ intra-peritoneal injections of cucurbitacin B resulted in $\sim 50 \%$ tumor size growth suppression.

Duangmano et al (47) reported that cucurbitacin B inhibited telomerase activity in the breast cancer cells. Telomere erosion and telomerase inhibition was supported with the inhibition of hTERT and cMYC proteins and consequential cell cycle arrest into $\mathrm{G}_{2} / \mathrm{M}$ phase $(47,48)$. Two years later they reported downregulation of cyclin B1 (key cell cycle regulatory protein) by cucurbitacin B (10). They also showed inhibition of phosphorylation of GSK-3 $\beta$, resulting in enhanced activity of the $\beta$-catenin-degradation complex, accompanied with downregulation of galectin-3. These results indicated an over obstruction of canonical Wnt/ $\beta$-catenin signaling axis. They also reported the role of neucleophosmin/B23 in breast cancer cells (49). Nucleophosmin/B23 protein plays an important role in controlling cellular cycling activities, and continuously patrols from nucleolus to cytoplasm and back. Microtubules are cytoskeleton builders consisting of $\alpha$-tubulin and $\beta$-tubulin subunit chains, and have fundamental role in maintaining cell structure, motility, trafficking and division. Shortage of nucleophosmin/B23 may lead to disruption of tubulin subunit polymerization. The authors found that cucurbitacin B treatment caused strong anti-proliferative and apoptotic effects in breast cancer cells through downregulation of nucleophosmin/ B23 and disruption of microtubule polymerization. They investigated the effectiveness of cucurbitacin B in BRCA1-defective breast cancer cells (50), where it counterpoised uncontrolled proliferation and drug resistance of cancer cells. Additionally, it caused upregulation in the expression of cell cycle inhibitors $\mathrm{p} 21^{\mathrm{WAF} 1}$ and $\mathrm{p} 27^{\mathrm{KIP} 1}$, driving the cells into apoptosis.

HER2 status and integrins play a vital role in the carcinogenesis in breast cancer cells. HER2/neu, a proto-oncogenic protein, is a mitogenic tyrosine kinase receptor, which directly participates in cell transformation, survival and proliferation. Integrins are a large family of extracellular matrix (tumor cell microenvironment governing) receptor proteins, composed of two $\alpha$ - and two $\beta$-glycoprotein units linked with non-covalent bonds. There are $\sim 24$ popular integrin dimers, distinctly mended by at least $18 \alpha$ and $8 \beta$ subunits. Integrins ITGAVB3 and ITGA6B4 specifically foster survival and cell motility (51-53), whereas ITGB1 and ITGB3 induce apoptosis (integrin-mediated cell death) $(54)$. Gupta and Srivastava $(55,56)$ reported that cucurbitacin B treatment inhibited HER 2 receptor and cell adhesion integrins, and triggered integrin-mediated cell death via B1 and B3 upregulation through a dose- and time-dependent BAX and caspase- 8 cleavage. They also reported that cucurbitacin B treatment in HER2 ${ }^{+}$breast cancer cells reduced their invasiveness by EMT reversal. HER2 ${ }^{+}$cells acquire mesenchymal properties via upregulation of TGF $\beta$ and downregulation of E-cadherin (57). Cucurbitacin B inhibited the expression of TGF $\beta$, SMAD, SNAIL, SLUG, ZEB1 and N-cadherin, and abrogated the expression of E-cadherin in HER2 ${ }^{+}$breast cancer cells. Cucurbitacin B treatment induced autophagy in breast cancer cells (58). It caused DNA damage in HER2-breast cancer cells via ROS mediated upregulation of $\gamma \mathrm{H}_{2} \mathrm{AX}$ and phosphorylation of ATM/ATR resulting in p53-dependent cell apoptosis. Autophagy induction was confirmed by the appearance of autophagic vacuoles in monodansylcadaverine (MDC) staining and upregulation of Beclin1, ULK1 and LC3 in a time- and dose-dependent manner. The effects of ROS reversed if the cells were pretreated with NAC. Cucurbitacin B also reduced the metastatic potential of the breast cancer cells (59). At the non-apoptotic dose, cucurbitacin B delayed migration and invasion potential of the breast cancer and human vascular endothelial cells in a time- and dose-dependent manner. It was further accompanied by inhibition of angiogenesis potential and a dose-dependent suppression of VEGF/FAK/MMP9 signaling axis. These results were validated via retrograde inhibition of FAK using its inhibitor FI14 and genetic silencing, and in vivo studies.

Lung cancer. Lang et al (60) tested the effect of cucurbitacin B on NSCLC cells. They showed that the highly oxygenated bitter triterpene (cucurbitacin B) caused moderate to potent cytotoxicity with $\mathrm{IC}_{50} 0.13 \mu \mathrm{M}$ in $48 \mathrm{~h}$ and $0.04 \mu \mathrm{M}$ in $72 \mathrm{~h}$. Thiols are one of the crucial redox regulators for cytoskeleton remodeling, cell cycle progression, mitochondrial apoptosis and regulation of redox sensitive signal transducers and activators of transcriptors. Kausar et al (61) showed that the thiols act as the intermediate between Cucurbitacin B and its toxicity in lung cancer cells. All cytotoxic effects were attenuated with thiol anti-oxidant NAC pretreatment, whereas exacerbated with GSH synthesis inhibitor BSO. They demonstrated the physical interaction of cucurbitacin B with NAC and glutathione (GSH) extracellularly using ultraviolet (UV) and FTICR mass spectrometry. Furthermore, Guo et al (62) reported that cucurbitacin B in lung cancer cells also caused DNA damage via ROS formation and let cells into $G_{2} / M$ cell cycle arrest. ROS caused double stranded DNA breaks, which led to ATM-mediated activation of Chk1-Cdc25C-Cdk1 and p53-14-3-3-o-CDC-25C-CDK1 pathways leading to mitotic interruption in parallel. Lung cancer when treated with cucurbitacin B inhibited phosphorylation of STAT3 to cause growth arrest and apoptosis in dose- and time-dependent manner (63). It inhibited STAT3 pathway leading to downregulation of cyclin B1 and BCL2. Shukla et al (64) reported global DNA methylation-associated epigenetic modifications due to cucurbitacin B treatment in highly aggressive NSCLC cells. They reported that the altered histone modifications at the respective promoter sites caused upregulation of $\mathrm{p} 16^{\text {INK4A }}$ and $\mathrm{p} 21^{\mathrm{WAF} 1}$ and downregulation of hTERT to cause replicative senescence, growth arrest and apoptosis. They also found that cucurbitacin B caused downregulation of $\mathrm{cMYC} / \mathrm{kRAS}$ at only protein and not transcriptional level. 5-mC reduction was accompanied with downregulation of DNMTs, HDACs and SIRT and upregulation of CBP and PCAF. The results were validated using carcinogen NNK-induced lung tumorigenesis in mice, advocating epigenetic modulation to be a significant anticancer mechanism of cucurbitacin B.

Silva et al (65) reported PI3Kinase and MAPK pathway inhibition due to cucurbitacin $\mathrm{B}$ treatment. The treatment 
delayed cell migration, alleviated invasion potential and caused dose- and time-dependent apoptosis. It inhibited MMP release and FAK activation, and upregulated (activated) phospho-AKT, -ERK, -JNK and -NF- $\kappa$ Bp65. In another study, cucurbitacin $B$ exhibited a strong anti-metastatic potential in the NSCLC cells via downregulation of canonical Wnt/ $\beta$-catenin signaling axis (66). In both moderately aggressive and highly aggressive NSCLC cell lines in vitro, cucurbitacin B treatment delayed migration and impeded invasion with downregulation of Wnt3/Wnt3 $\alpha$, FZD7, $\beta$-catenin, MMP2, cMYC, cyclin D1, survivin and VEGF and upregulation of E-cadherin proteins. It also showed potent anti-angiogenic effects. These effects regressed upon the treatment with EMT inducer TGF $\beta$ or by retrograde genetic knockdown of $\mathrm{Wnt} 3 / \mathrm{Wnt} 3 \alpha$. All the results were validated using NNK-induced lung tumorigenesis in mice. Intraperitoneal injections of cucurbitacin B at $0.1 \mathrm{mg} / \mathrm{kg}$ body weight, administered thrice a week, reduced the tumor incidence, frequency and volume by $80-90 \%$ compared to vehicle group.

Skin cancer. In malignant melanoma, cucurbitacin B inhibited cell proliferation as well as their migratory potential (67). Treatment in a mouse melanoma cell line caused cell membrane blebbing and deformation and multiploidy, via ROS induction resulting in dose-dependent $\mathrm{G}_{2} / \mathrm{M}$ phase growth arrest. There was significant depletion and aggregation of $\mathrm{G}$-actin protein from the cellular cytoskeleton, reversed using NAC. NAC is an $\mathrm{N}$-acetyl derivative of $L$-cysteine and an established potent antioxidant. Inhibition of growth of subcutaneously implanted melanoma cells was validated using female C57BL/6 mice. Cofilin is an actin-depolymerization factor. It is regulated by phosphatidylinositol phosphate, $\mathrm{pH}$ variations, redox balance and competition with tropomyosins (68), activated by dephosphorylation at its serine residue 3 by chronotropin or slingshot phosphatases, and inactivated by phosphorylation via LIM or TES kinases (69). Rho-associated kinases indirectly modulate the stress fibers and focal adhesions (70). Cofilin and actin form rods and are implicated in the pathogenesis of neurogenerative disorders (71). Cucurbitacin B dramatically activated cofilin via thiol oxidation, which formed rod-like structures co-localizing with the actin (tandem rods) in melanoma cells (72). Rho kinase and LIMK were downregulated, which were reversed by the treatment of thiol-ROS-scavenger NAC. Cucurbitacin B induced slingshot homolog-1 dependent hyper activation of cofilin and formation of cofilin-actin rods downstream of actin aggregation. VASP, an F-actin barbed end binding protein facilitates actin filament elongation through interaction with $\mathrm{G}$-actin, profilin and other actin regulatory factors (73). It directly controls the assembly of the actinfilament mesh, transforms the morphology and behavior of membrane protrusion structures and also contributes to cell migration and adhesion. Cucurbitacin B induced VASP phosphorylation (deactivation) at serine 157 (74). It was mediated by cAMP independent activation of G $\alpha 13 /$ RhoA/PKA pathway, to generate VASP clumps. These clumps co-localized with amorphous actin aggregates, prior to the formation of highly ordered cofilin-actin rods in melanoma cells.

Brain cancer. Cucurbitacin B inhibited growth of human glioblastoma multiforme cells by intense disturbance in its internal cytoskeleton (75). Within 15-30 min of treatment, it caused loss of pseudopodia, multi-nucleation and skirting up of cells associated with disruption of actin and microtubules, but was followed by the activation of cell survival pathways. It also inhibited cell proliferation, decreased migration and caused cell cycle arrest in $\mathrm{G}_{2} / \mathrm{M}$ phase and apoptosis. After $30 \mathrm{~min}$ of treatment, it caused upregulation of phospho-p38, JNK, JUN and ERK in a time-dependent manner. This was validated using SP600125, a broad-spectrum anthrapyrazolone inhibitor of JNK. SP600125 blocked the effects of cucurbitacin B. The treated glioblastoma multiforme cells exhibited marked disintegration and rearrangement of filamentous actin and $\beta$-tubulin. Touihri-Barakati et al (76) recently found that the proliferation, adhesion and migration inhibition due to cucurbitacin B may be mediated through $\alpha 5 \beta 1$ integrins. Laminins and fibronectin are extracellularly present high molecular weight cell adhesion proteins, and constitute major component of basal lamina contributing to cell adherence, dissemination and differentiation. Their upregulation is commonly found in EMT. Authors found significant downregulation of Laminin-1 and fibronectin in human glioblastoma cells. Further introspection in microvasculature endothelial cells demonstrated potent anti-angiogenic activity. Cucurbitacin B also showed remarkable anticancer effects in human neuroblastoma cancer cell lines (77). It induced $\mathrm{G}_{2} / \mathrm{M}$ arrest and apoptosis supported with upregulation of p53, p21 and BAX, and downregulation of BCL2. This was accompanied with the downregulation of proteins (CDK1 and cyclin B1) essential for cell cycle progression. It also inhibited JAK2/STAT3 signaling cascades and induced JNK/p38MAPK-activation/ERK-inactivation. Shang et al (78) reported that PTEN activation is crucial and adds positively to the anti-proliferative effects of cucurbitacin B. Apart from proliferation inhibition, cell cycle restraining and apoptotic trend, they dissected the possible mechanism of inhibition of AKT signaling pathway in human neuroblastoma cells. Although they found that some of the key down-stream factors in the pathway viz., NF- $\kappa$ B, AMPK and p38 did not alter; genetically activating AKT using plasmid vector carrying myr-AKT locus reversed the toxic effects of cucurbitacin B. Silencing of activated PTEN resulted in AKT phosphorylation and upregulation of the proapoptotic markers and repression of cyclins.

Liver cancer. Dat et al (40) isolated cucurbitacin B and its close relatives, which demonstrated potent anticancer activities mediated through HIF- $1 \alpha$ and NF- $\kappa$ B inhibition in hepatic carcinoma cells. Cucurbitacin $\mathrm{B}$ inhibited the activation of HIF- $1 \alpha$ in an artificially-induced hypoxia cell-based reporter assay and inhibited NF- $\mathrm{NB}$ in secreted alkaline phosphatase reporter assay. VEGF-specific ELISA validated its antiangiogenic potential. Chan et al (79) explored the activity of cucurbitacin B in human hepatocellular carcinoma in vitro and in vivo, where they reported that it caused dose- and time-dependent clonogenic inhibition via STAT3 independent S-phase arrest. This phenomenon occurred probably via ERK1/2 activation and suppression of cyclin D1, CDC2, and c-RAF phosphorylation. Cucurbitacin B induced ROS-mediated DNA damage leading to apoptosis and autophagy in hepatocellular carcinoma cells (80). It was supported with increased upregulation of $\gamma \mathrm{H}_{2} \mathrm{AX}$, phosphorylation of ATM/ATR 
and CHK1/CHK2, modulations in BCL2 family proteins and cleavage of caspases-7 and -9 . They also ascertained cucurbitacin B-induced autophagy, which was marked by vacuolization, upregulation of LC3II and ULK1, downregulation of AKT and mTOR proteins and activation of PTEN. They proposed that the contemporary activation of PTEN protein, which probably led to AKT/mTOR inhibition, had indirect correlation with autophagy. They used silencing RNA to genetically knock down PTEN gene to confirm inhibition of AKT and upregulation of autophagy specific proteins.

Blood cancer. Cucurbitacin $\mathrm{B}$ with variable $\mathrm{IC}_{50}$ value induced cell cycle arrest and cellular differentiation in acute promyelocytic and myeloid leukemia (81). It induced $\mathrm{S}$ phase growth arrest, swollen morphology of cells, altered cytoskeleton due to rapid and haphazard polymerization of filamentous actin into globular aggregates, and decreased clonogenicity in the immature blasts. It also caused upregulation of monocytic-/ granulocytic-specific CD11b, signifying cell differentiation. Cucurbitacin B suppressed the activated MAPK/ERK pathway and inhibited STAT3 activation in various human chronic myeloid leukemia cells (82). Protein expression analysis showed activation of STAT3, RAF, MEK and ERK proteins was inhibited. STAT3 activation modulation ensued through a crosstalk mechanism, which also resulted into $\mathrm{G}_{2} / \mathrm{M}$ arrest and apoptosis. Similar findings were noted in human leukemic Jurkat cells (83). Cucurbitacin B caused cofilin dephosphorylation and actin dynamics intrusion, prompting cell volume increase and simultaneous multi-nucleation. It also induced autophagosomes and LC3II upregulation as a compensatory protective response. Constitutive suppression of autophagy led to dramatic increase in caspase- 3 mediated autophagy.

Others. Gao et al (84) reported the anticancer effects of cucurbitacin B in prostate cancer cells. Cucurbitacin B caused selective toxicity in human epithelial type prostate cancer cells. ACLY is an enzyme, which metabolically converts mitochondrial citrate into acetyl coenzyme A $(85,86)$. Acetyl coenzyme A is a major precursor and constituent responsible for synthesis of fatty acids and mevalonate, which promote carcinogenesis. Cucurbitacin B downregulated the expression of acetyl coenzyme A, fatty acid synthesis and mevalonate, supplemented with mitochondrial ROS production. It was suggested that the inhibition of the acetyl coenzyme A signaling might be one of the downstream mechanisms of ROS-mediated intracellular insults leading into apoptosis. Cucurbitacin B exhibited significant toxicity in human laryngeal cancer cells leading to $G_{2} / M$ phase arrest (87). This was supported with downregulation of cyclin B1, phospho-STAT3 and BCL2, associated with chromatin condensation, nuclear fragmentation, and appearance of apoptotic bodies in a dose- and time-dependent manner. Cucurbitacin B inhibited proliferation and induced $\mathrm{G}_{0} / \mathrm{G}_{1}$ cell cycle arrest in a dose- and time-dependent manner in gastric cancer cells (88). It suppressed the expression of cyclin D1, cyclin E, CDK4 and CDK2 and upregulated the expression of p27, all of which are indicated in inhibition of cell cycle progression. It also inhibited phosphorylation of JAK2 and STAT3 and caused apoptosis. It also induced caspase-dependent apoptosis and autophagy in SGC7901/DDP DDP-resistant gastric cancer cells (89). It suppressed cell proliferation and induced apoptosis and autophagy via inhibition of activation of CIP2A-PP2A-mTORC1 axis. Cucurbitacin B was shown to cause cytotoxicity to a variety of bone cancer and normal cells at nanomolar doses (35). It forced osteoblastoma and normal lung fibroblasts into $\mathrm{G}_{2} / \mathrm{M}$ phase growth arrest, and unanimously activated p53 and pRB tumor suppressor pathways, leading to characteristic senescence-like growth arrest and/or apoptosis. At 20-100 $\mu \mathrm{M}$ dose it suppressed cell proliferation and induced apoptosis in U-2OS human osteosarcoma cells (90). It inhibited JAK2/STAT3 and MAPK pathways leading to BH3 domain and caspase family protein modulation to induce cell cycle arrest, along with MMP2, MMP9, VEGF inhibition adding up to delay in migration potential of the cells and angiogenesis inhibition. Cucurbitacin B showed anticancer activity in paclitaxel-resistant A2780/Taxol ovarian cancer cells (91). It caused growth inhibition in $\mathrm{G}_{2} / \mathrm{M}$ phase and apoptosis via upregulation of $\mathrm{p} 53$ and $\mathrm{p} 21$, downregulation of BCL2, activation of caspase-3, and suppression of P-gp, suggesting potential role against multidrug resistance clinical cancer. Ma et al (92) monitored hypoxia-induced signaling and modulation by cucurbitacin B in various cell lines in vitro. They found that the activation of HIF-1 $\alpha$-monomer was suppressed due to cucurbitacin B treatment in a dosedependent manner. They also found that this effect co-existed and correlated with strong dephosphorylation of mTOR, p70S6K, 4EBP1 and ERK1/2 proteins. It also downregulated the HIF-1 targets, VEGF and erythropoietin. Contemporary treatment with a known proteasomal inhibitor MG-132 overshadowed the hypoxia signaling suppression, implying that cucurbitacin B did not affect transcriptional coding, but regressed its ubiquitin-mediated proteasomal degradation. It also altered microtubule structures in human cervical cancer HeLa and osteosarcoma U-2OS cells (93). It affected mitotic spindles and induced $\mathrm{G}_{2} / \mathrm{M}$ cell cycle arrest. Zhang et al (94) showed that cucurbitacin B induced caspase-independent autophagy reflux in a variety of cell lines. It suppressed cell growth and proliferation, and inhibited interleukin- 6 mediated phosphorylation of STAT3 in a dose-dependent manner. Increase in mitochondrial-derived ROS and activated ERK1/2 and JNK proteins were also observed. It induced autophagy as evidenced by appearance of autophagosomes and upregulation of lipidated LC3 II. However, inhibition or knockdown of ATG5 and Beclin1 proteins did not rescue the cells from death. Instead, it forced cells to undergo caspase-dependent apoptosis, suggesting a competitive cross-relation between autophagy and apoptosis.

\section{Cucurbitacin B - as combination therapy}

Cucurbitacin B and its derivatives have shown synergism with other anticancer agents (reviewed in Table III). Marostica et al (95) presented DACE, a novel semisynthetic derivative of cucurbitacin B and tested its effect in NSCLC cells as individually and in combination with either cisplatin $(9 \mu \mathrm{M})$, irinotecan $(4.25 \mu \mathrm{M})$ or paclitaxel $(0.125 \mu \mathrm{M})(96)$. Cucurbitacin B $(20 \mathrm{mg})$ was made to react with $p$-toluenesulfonyl chloride $(34 \mathrm{mg})$ and $\mathrm{DABCO}(20 \mathrm{mg})$ in dichloromethane $(200 \mathrm{ml})$ to obtain tosylated intermediate $(20 \mathrm{mg})$, which was then made to undergo nucleophilic substitution using 


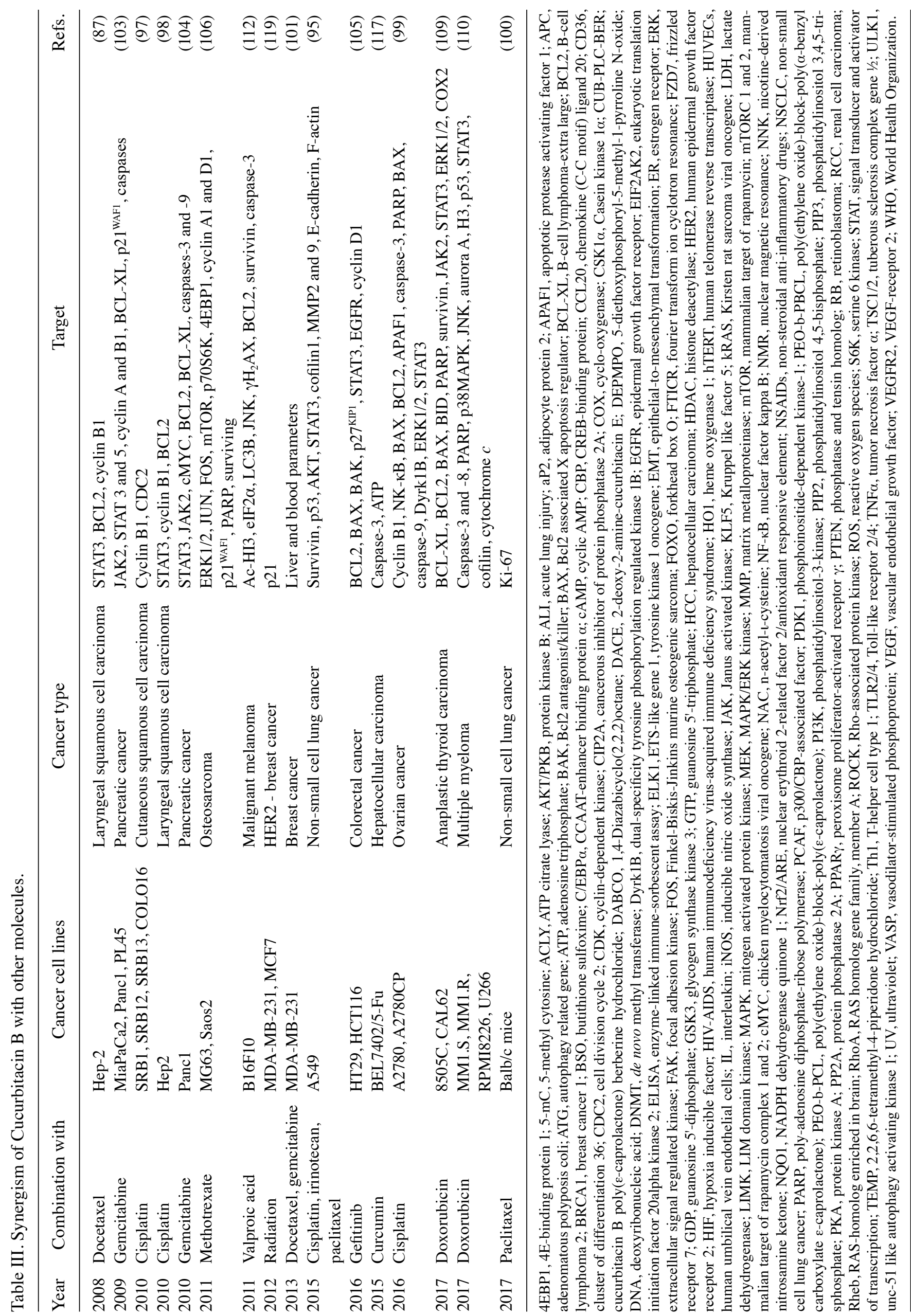


sodium azide $(18.2 \mathrm{mg})$ in dimethylformamide $(250 \mu \mathrm{l})$ to finally attain DACE. Cisplatin, an inorganic water-soluble platinum complex, reacts with and alters DNA after undergoing hydrolysis to produce crosslinks. Crosslinks impair DNA replication, and forces the cells into $G_{2}$ phase arrest. Irinotecan is a topoisomerase inhibitor. Paclitaxel is a cyclodecane isolated from the bark of Taxus brevifolia. It stabilizes microtubules when they are in polymerized form, which causes cell death. In combination with either one of three accomplices, DACE $(0.125 \mu \mathrm{M})$ reduced the risk of drug resistance, which is one of the major hurdles today in anticancer therapy by synthetic agents. It also showed selective toxicity to the cancer cells, forced them into $\mathrm{G}_{2} / \mathrm{M}$ phase cell cycle arrest via STAT3 activation suppression and AKT downregulation, filamentous actin aggregation, nuclear fragmentation, inactivated cofilin1 suppression and E-cadherin substantiation. DACE also interfered with the activation of EGFR and its downstream factors AKT, ERK, STAT3 and survivin, contributing to growth arrest and caspase-3-mediated apoptosis. Efficacy in combination with cisplatin has also been checked in cutaneous squamous cell carcinoma (97). Cucurbitacin B $(0.1-2.5 \mu \mathrm{M})$ with cisplatin $(5-20 \mu \mathrm{M})$ was pulse exposed to the cells i.e., exposed for a limited duration followed by culture in usual growth medium. The combination synergistically downregulated cyclin B1 and CDC2 expressions, with reduction in migratory and invasive potential of the cells. In laryngeal squamous cell carcinoma, the combination $(0.1 \mu \mathrm{M}$ cucurbitacin B, $10 \mu \mathrm{M}$ cisplatin) interdependently suppressed activation of STAT3 and translational expression of cyclin B1 and BCL2 (98). In ovarian cancer, cucurbitacin B sensitized cells to cisplatin (99). Cucurbitacin B $(2 \mu \mathrm{M})$ pretreated with cisplatin $(10 \mu \mathrm{M})$ resulted in enhanced cytotoxicity than that by cisplatin alone in both cisplatin sensitive and insensitive ovarian cancer cells, via depletion of glutathione and increase in ROS production. It downregulated Dyrk1B, phosphorylated ERK1/2 and STAT3 and cyclin B1, leading to $\mathrm{G}_{2} / \mathrm{M}$ phase growth arrest. It also downregulated BCL2 and APAF1 and upregulated caspase-9 indicating apoptotic induction. These effects afforded by the combination had cucurbitacin B at the dose of just a fourth of its $\mathrm{IC}_{50}$. Cucurbitacin $\mathrm{B}(1 \mathrm{mg} / \mathrm{kg})$ in combination with paclitaxel $(10 \mathrm{mg} / \mathrm{kg})$ injected intravenously suppressed tumor growth in Balb/c nude mice (100). Treatment was well tolerated by the animals and no evident damage in liver and kidneys was observed.

Docetaxel is a microtubule inhibitor. It prevents formation of microtubules leading to failure of growth and cell division. Gemcitabine, a nucleoside metabolic inhibitor, prevents the synthesis of genetic element, hence preventing DNA replication. Cucurbitacin B $(0.001-0.05 \mu \mathrm{M})$ synergistically enhanced the anti-proliferative and apoptosis effects of docetaxel $(0.001-0.005 \mu \mathrm{M})$ or gemcitabine $(0.001-0.1 \mu \mathrm{M})$ in breast cancer cells in vitro and in vivo, at much lower dose of either drug than that used in chemotherapy, indicating minimum adverse effects (101). However, even with combination, but at only high dose, myelosuppression, hepatotoxicity and leukopenia with gemcitabine combination was encountered. In another study, combination of cucurbitacin B $(1 \mu \mathrm{M})$ and docetaxel $(0.025 \mu \mathrm{M})$ caused cell cycle arrest at $\mathrm{G}_{2} / \mathrm{M}$ phase and apoptosis via synergistic suppression of phospho-STAT3, BCL2 and cyclin B1 in laryngeal cancer cells (102). Thoennissen et al (103) reported synergism of cucurbitacin $\mathrm{B}$ with gemcitabine in pancreatic cancer. Cucurbitacin B (0.01-0.1 $\mu \mathrm{M})$ and gemcitabine (0.001-0.01 $\mu \mathrm{M})$ combination caused dose-dependent multi-nucleation, $\mathrm{G}_{2} / \mathrm{M}$ arrest and apoptosis, associated with inhibition of activated JAK2, STAT 3/5, cyclin A/B1 and BCL-XL and activation of $\mathrm{p} 21^{\mathrm{WAF} 1}$ and caspases, more than cucurbitacin $\mathrm{B}$ $(0.05-0.2 \mu \mathrm{M})$ alone. The same group in another study in 2010 showed that this combination also inhibited BCL2 and cMYC adding up to apoptosis in pancreatic cancer cells in vitro. These effects were positively validated in vivo with only mild toxicity (104). Protein kinase activity is crucial for a majority of intra-cellular signaling pathways. Prevention of protein kinase results into cell growth arrest. Gefitinib is a protein kinase inhibitor and known to be orally active selective inhibitor of EGFR, which inhibits autophosphorylation of intracellular tyrosine residues. Cucurbitacin B at safe dose $(0.5 \mu \mathrm{M})$ offered synergistic anti-proliferative affects to benign dose of gefitinib $(10 \mu \mathrm{M})$ against human colorectal cancer cells in vitro (105), as validated via LDH assay. There was more significant downregulation of BCL2, cyclin D1, and phospho-EGFR and STAT3, and upregulation of BAX, BAK and p27KIP1, indicating stronger growth arrest and apoptotic signaling. Thymidylate is one of the important building blocks of DNA. Its synthesis is mainly stimulated by tetrahydrofolate. Methotrexate, an antineoplastic antimetabolite with immunosuppressant properties, is an inhibitor of tetrahydrofolate dehydrogenase. Cucurbitacin B $(0.07 \mu \mathrm{M})$ and methotrexate $(0.05 \mu \mathrm{M})$ combination caused $\mathrm{G}_{2} / \mathrm{M}$ growth arrest and apoptosis in human osteosarcoma cells (106). This was corroborated by inhibition of protein expression of ERK, AKT and mTOR in JAK/STAT inactive cells. Further in vivo validation exhibited tumor suppression by combination (cucurbitacin B at $0.5 \mathrm{mg} / \mathrm{kg}$ body weight, methotrexate at $150 \mathrm{mg} / \mathrm{kg}$ body weight) by $60-80 \%$, which held at $66 \%$ after methotrexate withdrawal. Doxorubicin, a topoisomerase inhibiting anthracycline, intercalates DNA and exerts its anticancer activity by the suppression of DNA polymerase, topoisomerase II, and methyltransferase (107). Doxorubicin-resistant cells are known to entail survivin super-expression (108). Cucurbitacin B $(0.2-1 \mu \mathrm{M})$ and doxorubicin (1-5 $\mu \mathrm{M})$ showed synergism against the progression of anaplastic thyroid cancer (109). They synergistically enhanced ROS production, with consequential upregulation of cleaved PARP, COX2 and phospho-ERK1/2, and downregulation of BCL2, survivin and JAK/STAT-signaling axis. In a recent study, cucurbitacin B (up to $0.2 \mu \mathrm{M}$ ) with doxorubicin (up to $0.2 \mu \mathrm{M}$ ) showed synergistic antitumor activity via inhibition of aurora A leading to $G_{2} / M$ phase cell cycle arrest, and IL10-induced STAT3 phosphorylation inhibition (110). It also induced cofilin dephosphorylation and caspase-mediated apoptosis.

Valproic acid, popular anti-convulsion and mood stabilizing fatty acid, is inhibited by histone deacetylase (drug resistance). Histone deacetylase activates tumor suppressors p53, p21 and CDKs, and increase histone acetylation, which suppress the activation of many proto-oncogenes (111). Cucurbitacin B caused dose-dependent toxicity in mouse melanoma cells, followed by multiploidy, autophagy and BCL2 upregulation for cell survival (112). This demonstrated the prosurvival 
role of autophagy in cancer cells after treatment with cucurbitacin $\mathrm{B}(1 \mu \mathrm{M})$. When administered in combination with valproic acid (1-5 $\mathrm{mM})$, it showed synergism to sensitize the cells to the toxicity due to valproic acid. It henceforth caused cell apoptosis and tapered multiploidization. Curcumin, obtained mainly from Curcuma longa, a yellow-orange phytopolyphenolic pigment commonly known as turmeric, is known for its medicinal properties such as anti-oxidant (prevention of ROS production), anti-inflammatory (COX inhibition) and anticancer (suppression of protein kinase $\mathrm{C}$ ). It showed potency against alcoholic liver injury and insult due to lipopolysaccharide, D-(+)-galactosamine and heavy metals (113-115). It fundamentally operates via mitochondrial invasion and is relatively safe to the healthy tissue (116). Combination of cucurbitacin $\mathrm{B}(143.2 \mu \mathrm{M})$ and curcumin (108.6 $\mu \mathrm{M})$ showed synergism dose- and time-dependently against the human hepatocellular carcinoma (117), forcing the cells into $\mathrm{G}_{0} / \mathrm{G}_{1}$ phase arrest and apoptosis. It decreased the sensitivity of the cells to P-glycoprotein and reversed the resistance to 5-fluorouracil, indicating reversal of multidrug resistance. In vivo validation using cucurbitacin B $(10 \mathrm{mg} / \mathrm{kg}$ body weight) and curcumin ( $5 \mathrm{mg} / \mathrm{kg}$ body weight) combination resulted in greater suppression in tumor growth than with either molecule alone, with enhanced caspase-3 activity and reduced ATP contents. Cucurbitain B in combination with glycosides exhibited excellent antioxidant properties in a dosedependent manner (118). The combination inhibited hydroxyl radical-dependent DEPMPO-hydroxyl radical adduct formation, superoxide radical anion-dependent DEPMPO-hydroxyl radical addict formation and singlet oxygen-dependent TEMPsinglet oxygen addict generated in the photoradiation-porphin system. Duangmano et al (119) reported that cucurbitacin B increased the sensitivity of HER2-negative breast cancer variants to radiotherapy, and caused dose-dependent $G_{2} / M$ phase arrest and apoptosis in vitro via progressive upregulation of the p21 mRNA. Further augmentation with irradiation resulted in rapid cell death. Cucurbitacins, Picracin and deacetylpicracin from Picrorhiza scrophulariiflora inhibited mitogen-induced T cell proliferation and IL-2 (120). Authors regarded picracin as more active in inducing apoptosis of non-stimulated $\mathrm{T}$ cells than the others.

\section{Cucurbitacin B - other biological systems}

Potential of cucurbitacin B against cardiac, liver, lung, neuronal and skin injuries, systemic infections, inflammation, sex-related behavior and adipocyte differentiation has also been explored. Cucurbitacins exhibit a broad range of pharmacological properties such as anti-inflammatory, antioxidant, antiviral, antipyretic, analgesic and anti-malarial (121-123). Cucurbitacin B $(0.2 \mathrm{mg} / \mathrm{kg})$ offered protection against pressure-overload cardiac hypertrophy with potent antihypertrophy and anti-fibrosis effects (124). Male C57/BL6 mice were given surgical aortic banding to induce cardiac hypertrophy. Cucurbitacin B fed mice demonstrated a significant reduction in heart weight, myocardial cell cross sectional area and interstitial fibrosis. These effects were further accompanied with inhibition of hypertrophy in phenylephrine stimulated cardiomyocytes attributed to inhibition of AKT/ mTOR/FOX03A axis and autophagy. Cucurbitacin B may be indicated in sepsis-induced acute lung injury (ALI) (125). A rat ALI model following abdominal septic puncture was treated with cucurbitacin B intraperitoneally. Cucurbitacin B-treated rats showed an increase in arterial oxygen partial pressure, and reduction in lung effusion, protein content, neutrophils and lymphocytes, and cytokines in a dose-dependent manner, with 3- to 5-fold increment in survival. Histological examination revealed that the pulmonary destruction was alleviated with cucurbitacin B treatment, endorsing its anti-oxidant and anti-inflammatory properties. Cucurbitacin B offered hepatoprotective and anti-inflammatory effects in artificially induced acute liver damage in outbred albino male Wistar rats (126). Flower-squeezed-sterile-juice of cucurbitacin B administered orally at $200-700 \mu \mathrm{l} / \mathrm{kg}$ body weight for three days before artificial induction of carbon chloride mediated hepatotoxicity resulted in mild and reversible damage in the liver parenchyma and liver function tests. However, higher dose showed signs of irreversible hepatotoxicity. Psoriasis is a chronic keratinocyte inflammatory adaptive immune-mediated disease, involving Th1-type immune cells and cytokines, encompassing $\sim 0.5-3 \%$ human population globally. It is characterized by hyperproliferation, inflammation and abnormal keratinocyte differentiation. Keratinocytes act as the first line barrier in immune surveillance, and govern innate immunity via inflammation-associated molecules such as $\mathrm{NF}-\kappa \mathrm{B}$. Imiquimod is an analog of adenosine, a chemical stress inducer. Topical application of cucurbitacin B inhibited imiquimod-induced pathogenesis of psoriatic dermatitis (127). It caused growth inhibition of keratinocytes, which was mediated by inhibition of NF- $\kappa \mathrm{B}$ and STAT3 signaling leading to reduced expression of psoriatic IL8 and CCL20 cytokines, thus, reducing epidermal hyperplasia and psoriatic pathogenesis. Yesilada et al (42) indexed anti-inflammatory property of cucurbitacin B using Whittle method, using a fraction from the freeze-dried fruit juice of squirting cucumber Ecballium elaterium. They estimated dye leakage from the vascular tissue in orally fed mice. Vascular leakage corresponded to permeability and inflammatory response. Authors recorded an increase in permeability with cucurbiatcin B dose; however, $400 \mathrm{mg} / \mathrm{kg}$ body weight (highest) also imposed severe toxicity to the animals.

Likewise, the ameliorative anti-oxidant effects of cucurbitacin $\mathrm{B}$ and its relatives were shown as beneficial against the neuronal injury (128). It significantly inhibited neuroinflammatory mediators in TLR2/4 agonist-stimulated microglia. Excess TLR activated cytokine and complement proteins may result into neuronal injury and consequential cell death, mediated through pro-inflammatory cytokines (TNF $\alpha$ and IL1 $\beta / 6$ ), and JAK/STAT and NF- $\kappa$ B pathways. Pretreatment with cucurbitacin B suppressed the phosphorylation of JAK1, STAT1 and STAT3, NF- $\mathrm{B}$ transactivation and the cytokine release, resulting into attenuation of expression of iNOS and COX2. It enhanced the activity of Nrf2/ARE pathway to upregulate $\mathrm{HO} 1$ and NQO1, and inhibited caspase activity to offer significant neuroprotection. Rawat et al (43) also evaluated the anti-oxidant and anti-inflammatory potential of cucurbitacin B containing plant extracts. Extracts of cucurbits from L. siceraria, C. pepo and L. cylindrical by means of superoxide radical scavenging activity assay and catalase activity assay in the presence of xylene orange and Amplex ${ }^{\circledR}$ Red demonstrated potent radical scavenging activity. They also 
inhibited inflammation specific cytokines COX-1 and COX-2 in lipopolysaccharide-induced mouse serum. Cucurbitacun B with cucurbitacin $\mathrm{E}$ in the dichloromethanolic extract from the roots of Wilbrandia ebracteata Cogn. protected against inflammation and algesia in rats (129). Male Wistar rats were injected with inflammatory agent carrageenan in paws, which developed into inflammation. Inflammation was significantly less in rats fed with the extract. Furthermore, pain felt with acetic acid application in the inflamed area was significantly less as compared to the vehicle group.

Cucurbitacin B reduced the likelihood of onset of hepatocellular carcinoma by preventing STAT3 phosphorylation and consequent adipocyte accumulation (130). Phospho-STAT3 stimulates the regulation of pro-proliferative cyclin D1 and adipogenesis markers $\operatorname{PPAR} \gamma, \mathrm{aP} 2, \mathrm{C} / \mathrm{EBP} \alpha$, adiponectin and CD36 proteins, and inhibits adipocyte differentiation inhibitor KLF5. Seo et al (130) showed that cucurbitacin B suppressed the activation of STAT3, henceforth suppressing adipocyte differentiation and accumulation. Prevention of adipogenesis and lipid accumulation by $0.2-0.3 \mu \mathrm{M}$ cucurbitacin $\mathrm{B}$ was more promising than by $20 \mathrm{mM}$ resveratrol (standardized anti-adipogenic compound). Genetic silencing of STAT3 significantly attenuated the anti-adipogenic activity. Cucurbitacin B showed synergistic antibacterial and antiviral potential against Staphylococcus aureus and Herpes simplex virus-1 (131). Within a range of dose, cucurbitacin B in synergism with other antibiotics such as tetracycline and oxacillin inhibited the growth of clinical drug resistant variant of Staphylococcus aureus, as determined by microdilution method and checkboard assay. By means of plaque number reduction assay, it showed potent anti-HSV-1 potential, comparable to acyclovir. Cucurbitacin B treatment, however, led to decline in the sexual hormone and behavior in male moth Agrotis ipsilon (132). Cucurbitacin B as an antagonist of 20E/EcR/USP complex and signaling pathway staging crucial for sexual behavior from the male antennal lobe reduced the amount of AipsEcR and AipsUSP in a dose-dependent manner, which inhibited central pheromone processing in the adult sexually mature male moth.

\section{Cucurbitacin B - toxicity}

Cucurbitacin B to the best of our knowledge has not been included in toxic or restricted use by any of the drug and safety bureau across the world, nor is there any report claiming its toxic role in vivo across the world (133), except an FDA report from 1955 and follow-up in 1983, where the authors reported that the median lethal dose of cucurbitacin B via intraperitoneal route was $\sim 1 \mathrm{mg} / \mathrm{kg}$ in male albino mice at the end of three doses (134). Cause of death was acute pulmonary edema and respiratory arrest. Smit in 2000 (135) reported that in rabbits the median lethal dose of cucurbitacin B was $0.5 \mathrm{mg} / \mathrm{kg}$ body weight after intravenous administration (136). Ferguson et al (137) also reported poisoning after human consumption of $700 \mathrm{~g}$ of commercially produced Cucurbita pepo L. within 6-h period. Toxic symptoms included bitter taste in mouth, abdominal cramps, diarrhea, and occasional vertigo and syncope. Australian Therapeutic Goods Administration has listed cucurbitacin B free from restricted use and encourages its use in combination with other agents (138).
Cucurbitacin B in its pure form had median lethal dose of $\sim 5 \mathrm{mg} / \mathrm{kg}$ (oral route) (139) and $1 \mathrm{mg} / \mathrm{kg}$ (intraperitoneal) (134) in mice, $0.5 \mathrm{mg} / \mathrm{kg}$ (intravenous) (140) in rabbit, and $0.32 \mathrm{mg} / \mathrm{kg}$ (intravenous) (141) in cat, recorded so far. Deaths at this dose were accompanied with symptoms such as pulmonary edema, however, with no mention of additional symptoms. Furthermore, severe toxicity leading to death following oral administration were reported in various studies reporting the use of plant and extracts - Ecballium elaterium in rabbits caused nervousness, restlessness, seizures, anorexia, tachycardia, tachypnea, dyspnea, cyanosis, and diarrhea eventually leading to death $(142,143)$; Cucurbita texana in Swiss Webster mice caused severe anemia followed by death (144); Citrullus colosynthis and Lagenaria siceraria in goats caused restlessness, anorexia, diarrhea, dehydration, anemia, dyspnea, kinetic latency, internal hemorrhages, pulmonary emphysema, enteritis, multi-organ failure, and eventually death (145); and Citrullus colocythis in Bovans-type chicks led to hepatic fatty changes and toxicity, catarrhal enteritis, pulmonary emphysema and renal tubular necrosis, but these symptoms reversed after 4 weeks of withdrawal (146).

Various human toxicity complaints have been reported from around the world after accidental or intentional consumption of fruit juice of zucchini squash $(142,147,148)$. Symptoms reported were similar to those in the in vivo studies pivoting digestive and neurological systems. However, following topical application with the same extract the human subjects remained asymptomatic (149). Since the median lethal dose via oral route was significantly higher than the parenteral, possibly digestion, emergence of metabolites and their absorption from the gut before reaching systemic circulation is crucial to alleviate its toxic effects and liberate its medicinal potency. Moreover, oral feeding led toxicities and deaths involved components additional to cucurbitacin B, advocating bail for cucurbitacin B off severely toxic profile. Therefore, oral administration of purified form of cucurbitacin B as an independent executor may be justified, as long as the dosage is conscientiously tailored and the symptoms are cautiously checked.

\section{Cucurbitacin B - biological supply chain and future scope}

The natural origin and synthetic production of cucurbitacin B have been extensively studied over the last few decades. Jung and Lui (150) presented the artificial convergent edifice efforts. Razavilar and Choi (151) found that the diffusivity of cucurbitacin B depends on wiggling motion of the block copolymers to diffuse while the contemporaneous water molecules diffusion via a hopping mechanism. Toker et al (152) proposed a novel method to naturally increase the yield of cucurbitacin B using Ecballium elaterium callus culture technique. They showed that the subculture calluses of stem explants incubated in medium supplemented with $1 \mathrm{mg} / \mathrm{l}$ benzyl adenine and $0.1 \mathrm{mg} / \mathrm{l}$ naphthalene acetic acid could competently accrue the compound. Mei et al (153) suggested a process for cucurbitacin B bioproduction from one of its parent glycoside using a specific Streptomyces sp., by enzyme broth incubation and extraction with ethyl acetate. The process was mild, simple and prolific; nevertheless, its hydrophobic and electrostatic structure left it prognostically difficult. 
Quick exploitation followed by attenuated performance of cucurbitacin B may abete solid doubts about the treatment modality and dosage in practical use. Cucurbitacin B is hydrophobic, hence suffers in situ absorption. Its absorption from carboxymethyl chitosan films loaded with phospholipidbile salt-mixed micelles as mucoadhesive buccal films resulted in 2.69-fold increase in bioavailability (154), with no toxic effect on buccal mucosa. Molavi et al (155) prepared polymeric micelles of less than 90 nanometers by encapsulating cucurbitacin $\mathrm{B}$ in PEO- $b$-PCL and PEO- $b$-PBCL. PEO-b-PCL micelles showed superiority in maintaining a sustained release of hydrophobic cucurbitacin B, thereby limiting the rate of STAT3 activation in murine cancer cell line. Patel et al (156) with the help of molecular dynamics simulation studies predicted that the increasing PCL/PEO ratio in PEO-b-PCL-cucurbitacin $\mathrm{B}$ micelles would reduce the drug release rate, due to polar intermolecular interactions. Docking energy analysis showed that the increase in ratio would favor additional hydrogen bond formation between the molecule and poly( $\varepsilon$-caprolactone). Cheng et al (157) prepared berberine hydrochloride modified phospholipid complex loaded cucurbitacin B (CUB-PLC-BER) as a formulation and tested its delivery and efficacy against cholangiocarcinoma in 2015. Berberine hydrochloride is known to stimulate bile release, hence was believed to contribute to sustained and prolonged drug release. Cucurbitacin B loaded with phospholipids and berberine hydrochloride had higher drug delivery rate, and was more cytotoxic to the cancer cells in both in vitro and in vivo. Wang et al (158) encapsulated cucurbitacin B in glycosylated solid lipid nanoparticles. Administration of the formulation resulted into significant increase in targeted cytotoxicity, with overall target specific efficiency of nearly $64 \%$, where the conventional formulations showed only $23-26 \%$.

You et al (159) predicted the direct relation between the STAT3 protein localization and autophagy. STAT3 in cytoplasm inhibited autophagy via sequestration of EIF2AK2 and interaction with FOXO1/3. Cytoplasmic localization initiated direct protein-to-protein interaction and impeded autophagy by countervailing autophagy related proteins. Nuclear STAT3 attuned autophagy via transcriptional regulation of autophagyrelated genes such as the BCL2 family. It is mediated at the genetic level where STAT3 activation may prompt genetic remodeling and attenuation of autophagy. Mitochondrial translocation of STAT3 constitutively suppressed autophagy. Studies reported that cucurbitacin B and derivatives interfered with the activation of STAT3 $(61,63,74,82,87,88,94,95,98,99$, $102-105,109,110,119,130)$. Autophagy signaling is a fairly new subject. Cucurbitacin B and its role in autophagy is mostly unexplored, hence the field is wide blank to fill in.

\section{Summary}

Cucurbitacins, steroids derived from triterpene hydrocarbon, found in a number of plant families, are some of the principle compounds, which attribute medicinal qualities to the plant. Cucurbitacin B, the bitter toxin, in previous few decades has splendidly verified its cytotoxic potential against cancer and other medical conditions. Through various mechanisms, it suppressed the pathogenesis and inhibited the spread of cancer in vitro and in vivo (Figs. 1 and 3). It did so via onset of tumor suppressor $\mathrm{p} 53$ pathway and inhibition of tumor progression

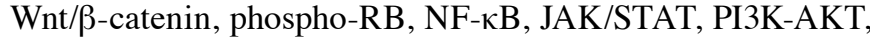
and MAPK/ERK pathways. Treatment with cucurbitacin $B$ consistently upregulated DNA damage and pro-apoptotic protein markers, while downregulated pro-survival markers, growth receptors and cell cycle progressors at either transcriptional level or via their ubiquitination and proteasomal degradation. Consequently, it caused growth arrest, apoptosis, cellular differentiation, and inhibition of proliferation in cancer cells. It also showed significant efficacy against the developing detrimental effects of cardiac, pulmonary, neurological and hepatic injuries, psoriasis, infections and lipogenesis. It also caused STAT3 dependent autophagy. Bio-production, efficacy and metabolism of the compound may be improved by means of slight chemical modulation such as the use of hydroponics, biotransformers, micelles and nanomaterials. It is not difficult to categorize cucurbitacin B as an effective anticancer molecule. It has the potential to prevent cancer, delay its progression, and might be able to completely cure it. Since it is procured from the natural sources, it could significantly economize the expenditure against the continuously growing disease. Surprisingly, not one human study to explore the efficacy of the molecule has been conducted so far. Clinical trials for cucurbitacin B as the mainline-targeted anticancer therapy either as an independent effector or as a supplement is warranted.

\section{Acknowledgements}

The present study was supported by grants from the Department of Biotechnology (Government of India) and the National Institute of Advanced Industrial Science and Technology, Japan.

\section{References}

1. Massagué $\mathrm{J}$ and Obenauf AC: Metastatic colonization by circulating tumour cells. Nature 529: 298-306, 2016.

2. World Health Organization: International Agency for Research on Cancer: World cancer factsheet. Cancer Research UK. http://gicr. iarc.fr/public/docs/20120906-WorldCancerFactSheet.pdf. Accessed June 20, 2017.

3. Cheung EC and Vousden $\mathrm{KH}$ : The role of p53 in glucose metabolism. Curr Opin Cell Biol 22: 186-191, 2010.

4. Engelmann D and Pützer BM: Emerging from the shade of p53 mutants: N-terminally truncated variants of the p53 family in EMT signaling and cancer progression. Sci Signal 7: re9, 2014.

5. Hengartner MO: The biochemistry of apoptosis. Nature 407: 770-776, 2000.

6. Kamijo T, Zindy F, Roussel MF, Quelle DE, Downing JR, Ashmun RA, Grosveld G and Sherr CJ: Tumor suppression at the mouse INK4a locus mediated by the alternative reading frame product p19ARF. Cell 91: 649-659, 1997.

7. Korenjak $\mathrm{M}$ and Brehm A: E2F-Rb complexes regulating transcription of genes important for differentiation and development. Curr Opin Genet Dev 15: 520-527, 2005.

8. Sharpless NE, Alson S, Chan S, Silver DP, Castrillon DH and DePinho RA: p16 ${ }^{\mathrm{INK} 4 \mathrm{a}}$ and $\mathrm{p} 53$ deficiency cooperate in tumorigenesis. Cancer Res 62: 2761-2765, 2002.

9. Stott FJ, Bates S, James MC, McConnell BB, Starborg M, Brookes S, Palmero I, Ryan K, Hara E, Vousden KH, et al: The alternative product from the human CDKN2A locus, p14 ${ }^{\mathrm{ARF}}$, participates in a regulatory feedback loop with p53 and MDM2. EMBO J 17: 5001-5014, 1998.

10. Dakeng S, Duangmano S, Jiratchariyakul W, U-Pratya Y, Bögler $\mathrm{O}$ and Patmasiriwat $\mathrm{P}$ : Inhibition of Wnt signaling by cucurbitacin B in breast cancer cells: Reduction of Wnt-associated proteins and reduced translocation of galectin-3-mediated $\beta$-catenin to the nucleus. J Cell Biochem 113: 49-60, 2012. 
11. Nefedova Y and Gabrilovich DI: Targeting of Jak/STAT pathway in antigen presenting cells in cancer. Curr Cancer Drug Targets 7: 71-77, 2007.

12. Hung MH, Tai WT, Shiau CW and Chen KF: Downregulation of signal transducer and activator of transcription 3 by sorafenib: A novel mechanism for hepatocellular carcinoma therapy. World J Gastroenterol 20: 15269-15274, 2014.

13. Hossain DM, Pal SK, Moreira D, Duttagupta P, Zhang Q, Won H, Jones J, D'Apuzzo M, Forman S and Kortylewski M: TLR9-targeted STAT3 silencing abrogates immunosuppressive activity of myeloid-derived suppressor cells from prostate cancer patients. Clin Cancer Res 21: 3771-3782, 2015.

14. Liu H, Ren G, Wang T, Chen Y, Gong C, Bai Y, Wang B, Qi H, Shen J, Zhu L, et al: Aberrantly expressed Fra1 by IL6/STAT3 transactivation promotes colorectal cancer aggressiveness through epithelial mesenchymal transition. Carcinogenesis 36 459468, 2015.

15. Peyser ND, Freilino M, Wang L, Zeng Y, Li H, Johnson DE and Grandis JR: Frequent promoter hypermethylation of PTPRT increases STAT3 activation and sensitivity to STAT3 inhibition in head and neck cancer. Oncogene 35: 1163-1169, 2016.

16. Wen W, Wu J, Liu L, Tian Y, Buettner R, Hsieh MY, Horne D, Dellinger TH, Han ES, Jove R, et al: Synergistic anti-tumor effect of combined inhibition of EGFR and JAK/STAT3 pathways in human ovarian cancer. Mol Cancer 14: 100, 2015.

17. Yao X, Liu H, Zhang X, Zhang L, Li X, Wang C and Sun S: Cell surface GRP78 accelerated breast cancer cell proliferation and migration by activating STAT3. PLoS One 10: e0125634, 2015.

18. Yoon J, Ko YS, Cho SJ, Park J, Choi YS, Choi Y, Pyo JS, Ye SK, Youn HD, Lee JS, et al: Signal transducers and activators of transcription 3-induced metastatic potential in gastric cancer cells is enhanced by glycogen synthase kinase-3 $\beta$. APMIS 123 373-382, 2015.

19. Royds JA, Dower SK, Qwarnstrom EE and Lewis CE: Response of tumour cells to hypoxia: Role of p53 and NF- $\kappa \mathrm{B}$. Mol Pathol 51: 55-61, 1998.

20. Bulavin DV and Fornace AJ Jr: p38 MAP kinase's emerging role as a tumor suppressor. Adv Cancer Res 92: 95-118, 2004.

21. Pal I and Mandal M: PI3K and Akt as molecular targets for cancer therapy: Current clinical outcomes. Acta Pharmacol Sin 33: 1441-1458, 2012.

22. Harley CB: Aging of cultured human skin fibroblasts. Methods Mol Biol 5: 25-32, 1990.

23. Hayflick L: The limited in vitro lifetime of human diploid cell strains. Exp Cell Res 37: 614-636, 1965.

24. Kimmelman AC and White E: Autophagy and tumor metabolism. Cell Metab 25: 1037-1043, 2017.

25. Kaefer CM and Milner JA: Herbs and Spices in Cancer Prevention and Treatment. Herbal Medicine: Biomolecular and Clinical Aspects. 2nd edition. CRC Press/Taylor \& Francis, 2011.

26. Kaushik U, Aeri V and Mir SR: Cucurbitacins - An insight into medicinal leads from nature. Pharmacogn Rev 9: 12-18, 2015.

27. Alghasham AA: Cucurbitacins - a promising target for cancer therapy. Int J Health Sci (Qassim) 7: 77-89, 2013.

28. Clericuzio M, Mella M, Vita-Finzi P, Zema M and Vidari G: Cucurbitane triterpenoids from Leucopaxillus gentianeus. J Nat Prod 67: 1823-1828, 2004.

29. Chen JC, Chiu MH, Nie RL, Cordell GA and Qiu SX: Cucurbitacins and cucurbitane glycosides: Structures and biological activities. Nat Prod Rep 22: 386-399, 2005.

30. Clericuzio M, Tabasso S, Bianco MA, Pratesi G, Beretta G, Tinelli S, Zunino F and Vidari G: Cucurbitane triterpenes from the fruiting bodies and cultivated mycelia of Leucopaxillus gentianeus. J Nat Prod 69: 1796-1799, 2006.

31. Wiart C: The definition and significance of Cucurbitacin B a STAT3 inhibitors. Cancer Lett 328: 188, 2013.

32. Dantas INF, Gadelha GCM, Chaves DC, Monte FJQ, Pessoa C, de Moraes MO and Costa-Lotufo LV: Studies on the cytotoxicity of cucurbitacins isolated from Cayaponia racemosa (Cucurbitaceae). Z Naturforsch C 61: 643-646, 2006.

33. Hatam NAR, Whiting DA and Yousif NJ: Cucurbitacin glycosides from Citrullus colocynthis. Phytohemistry 28: 1268-1271, 1989.

34. Abou-Khalil R, Jraij A, Magdalou J, Ouaini N, Tome D and Greige-Gerges $\mathrm{H}$ : Interaction of cucurbitacins with human serum albumin: Thermodynamic characteristics and influence on the binding of site specific ligands. J Photochem Photobiol B 95: 189-195, 2009.

35. Li K, Yu Y, Sun S, Liu Y, Garg S, Kaul SC, LeiZ, Gao R, Wadhwa R and Zhang Z: Functional characterization of anticancer activity in the aqueous extract of Helicteres angustifolia L. roots. PLoS One 11: e0152017, 2016.
36. Oberlies NH, Burgess JP, Navarro HA, Pinos RE, Soejarto DD, Farnsworth NR, Kinghorn AD, Wani MC and Wall ME: Bioactive constituents of the roots of Licania intrapetiolaris. $\mathrm{J}$ Nat Prod 64: 497-501, 2001

37. Beutler JA, McCall KL, Herbert K, Herald DL, Pettit GR, Johnson T, Shoemaker RH and Boyd MR: Novel cytotoxic diterpenes from Casearia arborea. J Nat Prod 63: 657-661, 2000.

38. Ayyad SEN, Abdel-Lateff A, Basaif SA and Shier T: Cucurbitacins-type triterpene with potent activity on mouse embryonic fibroblast from Cucumis prophetarum, cucurbitaceae. Pharmacognosy Res 3: 189-193, 2011.

39. Chen C, Qiang S, Lou L and Zhao W: Cucurbitane-type triterpenoids from the stems of Cucumis melo. J Nat Prod 72: 824-829, 2009.

40. Dat NT, Jin X, Hong YS and Lee JJ: An isoaurone and other constituents from Trichosanthes kirilowii seeds inhibit hypoxiainducible factor-1 and nuclear factor-kappaB. J Nat Prod 73: 1167-1169, 2010.

41. Wu KJ, Grandori C, Amacker M, Simon-Vermot N, Polack A, Lingner J and Dalla-Favera R: Direct activation of TERT transcription by c-MYC. Nat Genet 21: 220-224, 1999.

42. Yesilada E, Tanaka S, Sezik E and Tabata M: Isolation of an anti-inflammatory principle from the fruit juice of Ecballium elaterium. J Nat Prod 51: 504-508, 1988.

43. Rawat I, Sharma D and Goel HC: Antioxidant and anti-inflammatory potential of some dietary cucurbits. Oxid Antioxid Med Sci 3: 65-72, 2014.

44. Schabort JC and Potgieter JJ: A thin-layer and an improved paperchromatographic methods for the separation of Cucurbitacin B and 23,24-dihydrocucurbitacin B. J Chromatog 31: 235-237, 1967.

45. Tannin-Spitz T, Grossman S, Dovrat S, Gottlieb HE and Bergman M: Growth inhibitory activity of cucurbitacin glucosides isolated from Citrullus colocynthis on human breast cancer cells. Biochem Pharmacol 73: 56-67, 2007.

46. Wakimoto N, Yin D, O'Kelly J, Haritunians T, Karlan B, Said J, Xing H and Koeffler HP: Cucurbitacin B has a potent antiproliferative effect on breast cancer cells in vitro and in vivo. Cancer Sci 99: 1793-1797, 2008.

47. Duangmano S, Dakeng S, Jiratchariyakul W, Suksamrarn A, Smith DR and Patmasiriwat P: Antiproliferative effects of cucurbitacin B in breast cancer cells: Down-regulation of the c-Myc/ hTERT/telomerase pathway and obstruction of the cell cycle. Int J Mol Sci 11: 5323-5338, 2010.

48. Wu PL, Lin FW, Wu TS, Kuoh CS, Lee KH and Lee SJ: Cytotoxic and anti-HIV principles from the rhizomes of Begonia nantoensis. Chem Pharm Bull (Tokyo) 52: 345-349, 2004.

49. Duangmano S, Sae-Lim P, Suksamrarn A, Domann FE and Patmasiriwat P: Cucurbitacin B inhibits human breast cancer cell proliferation through disruption of microtubule polymerization and nucleophosmin/B23 translocation. BMC Complement Altern Med 12: 185, 2012.

50. Promkan M, Dakeng S, Chakrabarty S, Bögler O and Patmasiriwat P: The effectiveness of cucurbitacin B in BRCA1 defective breast cancer cells. PLoS One 8: e55732, 2013.

51. Boone JJ, Bhosle J, Tilby MJ, Hartley JA and Hochhauser D: Involvement of the HER 2 pathway in repair of DNA damage produced by chemotherapeutic agents. Mol Cancer Ther 8: 3015-3023, 2009.

52. Friedrichs K, Ruiz P, Franke F, Gille I, Terpe HJ and Imhof BA: High expression level of alpha 6 integrin in human breast carcinoma is correlated with reduced survival. Cancer Res 55: 901-906, 1995.

53. Jones JL, Royall JE, Critchley DR and Walker RA: Modulation of myoepithelial-associated alpha6beta4 integrin in a breast cancer cell line alters invasive potential. Exp Cell Res 235: 325-333, 1997.

54. Desgrosellier JS and Cheresh DA: Integrins in cancer: Biological implications and therapeutic opportunities. Nat Rev Cancer 10: 9-22, 2010 .

55. Gupta $P$ and Srivastava SK: Inhibition of Integrin-HER2 signaling by Cucurbitacin B leads to in vitro and in vivo breast tumor growth suppression. Oncotarget 5: 1812-1828, 2014.

56. Gupta P and Srivastava SK: HER 2 mediated de novo production of TGF $\beta$ leads to SNAIL driven epithelial-to-mesenchymal transition and metastasis of breast cancer. Mol Oncol 8: 1532-1547, 2014.

57. de Herreros AG, Peiró S, Nassour M and Savagner P: Snail family regulation and epithelial mesenchymal transitions in breast cancer progression. J Mammary Gland Biol Neoplasia 15: 135-147, 2010. 
58. Ren G, Sha T, Guo J, Li W, Lu J and Chen X: Cucurbitacin B induces DNA damage and autophagy mediated by reactive oxygen species (ROS) in MCF-7 breast cancer cells. J Nat Med 69: 522-530, 2015

59. Sinha S, Khan S, Shukla S, Lakra AD, Kumar S, Das G, Maurya R and Meeran SM: Cucurbitacin B inhibits breast cancer metastasis and angiogenesis through VEGF-mediated suppression of FAK/ MMP-9 signaling axis. Int J Biochem Cell Biol 77 (Pt A): 41-56, 2016.

60. Lang KL, Silva IT,Zimmermann LA, Machado VR, Teixeira MR Lapuh MI, Galetti MA, Palermo JA, Cabrera GM, Bernardes LS, et al: Synthesis and cytotoxic activity evaluation of dihydrocucurbitacin B and cucurbitacin B derivatives. Bioorg Med Chem 20: 3016-3030, 2012.

61. Kausar H, Munagala R, Bansal SS, Aqil F, Vadhanam MV and Gupta RC: Cucurbitacin B potently suppresses non-small-cell lung cancer growth: Identification of intracellular thiols as critical targets. Cancer Lett 332: 35-45, 2013.

62. Guo J, Wu G, Bao J, Hao W, Lu J and Chen X: Cucurbitacin B induced ATM-mediated DNA damage causes G2/M cell cycle arrest in a ROS-dependent manner. PLoS One 9: e88140, 2014.

63. Zhang M, Bian ZG, Zhang Y, Wang JH, Kan L, Wang X, Niu HY and He P: Cucurbitacin B inhibits proliferation and induces apoptosis via STAT3 pathway inhibition in A549 lung cancer cells. Mol Med Rep 10: 2905-2911, 2014.

64. Shukla S, Khan S, Kumar S, Sinha S, Farhan M, Bora HK, Maurya R and Meeran SM: Cucurbitacin B alters the expression of tumor-related genes by epigenetic modifications in NSCLC and inhibits NNK-induced lung tumorigenesis. Cancer Prev Res (Phila) 8: 552-562, 2015.

65. Silva IT, Geller FC, Persich L, Dudek SE, Lang KL, Caro MS, Durán FJ, Schenkel EP, Ludwig S and Simões CM: Cytotoxic effects of natural and semisynthetic cucurbitacins on lung cancer cell line A549. Invest New Drugs 34: 139-148, 2016.

66. Shukla S, Sinha S, Khan S, Kumar S, Singh K, Mitra K, Maurya R and Meeran SM: Cucurbitacin B inhibits the stemness and metastatic abilities of NSCLC via downregulation of canonical Wnt/B-catenin signaling axis. Sci Rep 6: 21860, 2016.

67. Zhang Y, Ouyang D, Xu L, Ji Y, Zha Q, Cai J and He X: Cucurbitacin B induces rapid depletion of the G-actin pool through reactive oxygen species-dependent actin aggregation in melanoma cells. Acta Biochim Biophys Sin (Shanghai) 43: 556-567, 2011.

68. Bamburg JR and Bernstein BW: Roles of ADF/cofilin in actin polymerization and beyond. F1000 Biol Rep 2: 62, 2010.

69. Wang W, Eddy R and Condeelis J: The cofilin pathway in breast cancer invasion and metastasis. Nat Rev Cancer 7: 429-440, 2007

70. Van Troys M, Huyck L, Leyman S, Dhaese S, Vandekerkhove J and Ampe C: Ins and outs of ADF/cofilin activity and regulation. Eur J Cell Biol 87: 649-667, 2008.

71. Bamburg JR, Bernstein BW, Davis RC, Flynn KC, Goldsbury C Jensen JR, Maloney MT, Marsden IT, Minamide LS, Pak CW, et al: $\mathrm{ADF} / \mathrm{Cofilin}$-actin rods in neurodegenerative diseases. Curr Alzheimer Res 7: 241-250, 2010.

72. Zhang YT, Ouyang DY, Xu LH, Zha QB and He XH: Formation of cofilin-actin rods following cucurbitacin-B-induced actin aggregation depends on Slingshot homolog 1-mediated cofilin hyperactivation. J Cell Biochem 114: 2415-2429, 2013.

73. Trichet L, Sykes $C$ and Plastino J: Relaxing the actin cytoskeleton for adhesion and movement with Ena/VASP. J Cell Biol 181: $19-25,2008$.

74. Zhang YT, Xu LH,Lu Q, Liu KP,Liu PY, JiF, Liu XM, Ouyang DY and He XH: VASP activation via the G $\alpha 13 /$ RhoA/PKA pathway mediates cucurbitacin-B-induced actin aggregation and cofilinactin rod formation. PLoS One 9: e93547,2014.

75. Yin D, Wakimoto N, Xing H, Lu D, Huynh T, Wang X, Black KL and Koeffler HP: Cucurbitacin B markedly inhibits growth and rapidly affects the cytoskeleton in glioblastoma multiforme. Int J Cancer 123: 1364-1375, 2008.

76. Touihri-Barakati I, Kallech-Ziri O, Ayadi W, Kovacic H, Hanchi B, Hosni K and Luis J: Cucurbitacin B purified from Ecballium elaterium (L.) A. Rich from Tunisia inhibits $\alpha 5 \beta 1$ integrin-mediated adhesion, migration, proliferation of human glioblastoma cell line and angiogenesis. Eur J Pharmacol 797: 153-161, 2017.

77. Zheng Q, Liu Y, Liu W, Ma F, Zhou Y, Chen M, Chang J, Wang Y, Yang $G$ and He G: Cucurbitacin B inhibits growth and induces apoptosis through the JAK2/STAT3 and MAPK pathways in SH-SY5Y human neuroblastoma cells. Mol Med Rep 10: 89-94, 2014.
78. Shang Y, Guo XX, Li WW, Rao W, Chen ML, Mu LN and Li SJ: Cucurbitacin-B inhibits neuroblastoma cell proliferation through up-regulation of PTEN. Eur Rev Med Pharmacol Sci 18 3297-3303, 2014

79. Chan KT, Meng FY, Li Q, Ho CY, Lam TS, To Y, Lee WH, Li M, Chu KH and Toh M: Cucurbitacin B induces apoptosis and S phase cell cycle arrest in BEL-7402 human hepatocellular carcinoma cells and is effective via oral administration. Cancer Lett 294: 118-124, 2010.

80. Niu Y, Sun W, Lu JJ, Ma DL, Leung CH, Pei L and Chen X: PTEN activation by DNA damage induces protective autophagy in response to cucurbitacin B in hepatocellular carcinoma cells. Oxid Med Cell Longev 2016: 4313204, 2016.

81. Haritunians T, Gueller S, Zhang L, Badr R, Yin D, Xing H, Fung MC and Koeffler HP: Cucurbitacin B induces differentiation, cell cycle arrest, and actin cytoskeletal alterations in myeloid leukemia cells. Leuk Res 32: 1366-1373, 2008.

82. Chan KT, Li K, Liu SL, Chu KH, Toh M and Xie WD: Cucurbitacin B inhibits STAT3 and the Raf/MEK/ERK pathway in leukemia cell line K562. Cancer Lett 289: 46-52, 2010.

83. Zhu JS, Ouyang DY, Shi ZJ, Xu LH, Zhang YT and He XH: Cucurbitacin B induces cell cycle arrest, apoptosis and autophagy associated with $\mathrm{G}$ actin reduction and persistent activation of cofilin in Jurkat cells. Pharmacology 89: 348-6, 2012.

84. Gao Y, Islam MS, Tian J, Lui VWY and Xiao D: Inactivation of ATP citrate lyase by Cucurbitacin B: A bioactive compound from cucumber, inhibits prostate cancer growth. Cancer Lett 349: $15-25,2014$

85. Zaidi N, Swinnen JV and Smans K: ATP-citrate lyase: A key player in cancer metabolism. Cancer Res 72: 3709-3714, 2012.

86. Zaytseva YY, Rychahou PG, Gulhati P, Elliott VA, Mustain WC, O'Connor K, Morris AJ, Sunkara M, Weiss HL, Lee EY, et al: Inhibition of fatty acid synthase attenuates CD44-associated signaling and reduces metastasis in colorectal cancer. Cancer Res 72: 1504-1517, 2012.

87. Liu T, Zhang M, Zhang H, Sun C and Deng Y: Inhibitory effects of cucurbitacin B on laryngeal squamous cell carcinoma. Eur Arch Otorhinolaryngol 265: 1225-1232, 2008.

88. Xie YL, Tao WH, Yang TX and Qiao JG: Anticancer effect of cucurbitacin B on MKN-45 cells via inhibition of the JAK2/ STAT3 signaling pathway. Exp Ther Med 12: 2709-2715, 2016.

89. Liu X, Duan C, Ji J, Zhang T, Yuan X, Zhang Y, Ma W, Yang J, Yang L, Jiang Z, et al: Cucurbitacin B induces autophagy and apoptosis by suppressing CIP2A/PP2A/mTORC1 signaling axis in human cisplatin resistant gastric cancer cells. Oncol Rep 38: 271-278, 2017.

90. Zhang ZR, Gao MX and Yang K: Cucurbitacin B inhibits cell proliferation and induces apoptosis in human osteosarcoma cells via modulation of the JAK2/STAT3 and MAPK pathways. Exp Ther Med 14: 805-812, 2017.

91. Qu Y, Cong P, Lin C, Deng Y, Li-Ling J and Zhang M: Inhibition of paclitaxel resistance and apoptosis induction by cucurbitacin B in ovarian carcinoma cells. Oncol Lett 14: 145-152, 2017.

92. Ma J, Zi Jiang Y, Shi H, Mi C, Li J, Xing Nan J, Wu X, Joon Lee J and Jin X: Cucurbitacin B inhibits the translational expression of hypoxia-inducible factor-1 $\alpha$. Eur J Pharmacol 723: 46-54, 2014.

93. Wang X, Tanaka M, Peixoto HS and Wink M: Cucurbitacins: Elucidation of their interactions with the cytoskeleton. PeerJ 5: e3357, 2017

94. Zhang T, Li Y, Park KA, Byun HS, Won M, Jeon J, Lee Y, Seok JH, Choi SW, Lee SH, et al: Cucurbitacin induces autophagy through mitochondrial ROS production which counteracts to limit caspase-dependent apoptosis. Autophagy 8: 559-576, 2012.

95. Marostica LL, Silva IT, Kratz JM, Persich L, Geller FC, Lang KL, Caro MSB, Durán FJ, Schenkel EP and Simões CM: Synergetic antiproliferative effects of a new cucurbitacin B derivative and chemotherapy drugs on lung cancer cell line A549. Chem Res Toxicol 28: 1949-1960, 2015.

96. Silva IT, Carvalho A, Lang KL, Dudek SE, Masemann D, Durán FJ, Caro MSB, Rapp UR, Wixler V, Schenkel EP, et al: In vitro and in vivo antitumor activity of a novel semisynthetic derivative of cucurbitacin B. PLoS One 10: e0117794, 2015.

97. Chen W, Leiter A, Yin D, Meiring M, Louw VJ and Koeffler HP: Cucurbitacin B inhibits growth, arrests the cell cycle, and potentiates antiproliferative efficacy of cisplatin in cutaneous squamous cell carcinoma cell lines. Int J Oncol 37: 737-743, 2010.

98. Liu T, Peng H, Zhang M, Deng Y and Wu Z: Cucurbitacin B, a small molecule inhibitor of the Stat 3 signaling pathway, enhances the chemosensitivity of laryngeal squamous cell carcinoma cells to cisplatin. Eur J Pharmacol 641: 15-22, 2010. 
99.El-Senduny FF, Badria FA, El-Waseef AM, Chauhan SC and Halaweish F: Approach for chemosensitization of cisplatinresistant ovarian cancer by cucurbitacin B. Tumour Biol 37: 685-698, 2016.

100. Marostica LL, de Barros ALB, Oliveira J, Salgado BS, Cassali GD, Leite EA, Cardoso VN, Lang KL, Caro MSB, Durán FJ, et al: Antitumor effectiveness of a combined therapy with a new cucurbitacin $\mathrm{B}$ derivative and paclitaxel on a human lung cancer xenograft model. Toxicol Appl Pharmacol 329: 272-281, 2017

101. Aribi A, Gery S, Lee DH, Thoennissen NH, Thoennissen GB, Alvarez R, Ho Q, Lee K, Doan NB, Chan KT, et al: The triterpenoid cucurbitacin $\mathrm{B}$ augments the antiproliferative activity of chemotherapy in human breast cancer. Int J Cancer 132: 2730-2737, 2013.

102.Liu T, Zhang M, Zhang H, Sun C, Yang X, Deng Y and Ji W: Combined antitumor activity of cucurbitacin $\mathrm{B}$ and docetaxel in laryngeal cancer. Eur J Pharmacol 587: 78-84, 2008.

103. Thoennissen NH, Iwanski GB, Doan NB, Okamoto R, Lin P, Abbassi S, Song JH, Yin D, Toh M, Xie WD, et al: Cucurbitacin B induces apoptosis by inhibition of the JAK/STAT pathway and potentiates antiproliferative effects of gemcitabine on pancreatic cancer cells. Cancer Res 69: 5876-5884, 2009

104. Iwanski GB, Lee DH, En-Gal S, Doan NB, Castor B, Vogt M, Toh M, Bokemeyer C, Said JW, Thoennissen NH, et al: Cucurbitacin B, a novel in vivo potentiator of gemcitabine with low toxicity in the treatment of pancreatic cancer. Br J Pharmacol 160: 998-1007, 2010.

105. Yar Saglam AS, Alp E, Elmazoglu Z and Menevse S: Treatment with cucurbitacin $B$ alone and in combination with gefitinib induces cell cycle inhibition and apoptosis via EGFR and JAK STAT pathway in human colorectal cancer cell lines. Hum Exp Toxicol 35: 526-543, 2016.

106. Lee DH, Thoennissen NH, Goff C, Iwanski GB, Forscher C, Doan NB, Said JW and Koeffler HP: Synergistic effect of low-dose cucurbitacin B and low-dose methotrexate for treatment of human osteosarcoma. Cancer Lett 306: 161-170, 2011.

107. Tacar O, Sriamornsak P and Dass CR: Doxorubicin: An update on anticancer molecular action, toxicity and novel drug delivery systems. J Pharm Pharmacol 65: 157-170, 2013.

108.Zhang Z, Zhang Y, Lv J and Wang J: The survivin suppressant YM155 reverses doxorubicin resistance in osteosarcoma. Int J Clin Exp Med 8: 18032-18040, 2015.

109. Kim SH, Kang JG, Kim CS, Ihm SH, Choi MG, Yoo HJ and Lee SJ: Doxorubicin has a synergistic cytotoxicity with cucurbitacin B in anaplastic thyroid carcinoma cells. Tumour Biol 39: $1010428317692252,2017$.

110. Yang T, Liu J, Yang M, Huang N, Zhong Y, Zeng T, Wei R, Wu Z, Xiao C, Cao X, et al: Cucurbitacin B exerts anti-cancer activities in human multiple myeloma cells in vitro and in vivo by modulating multiple cellular pathways. Oncotarget 8: 5800-5813, 2017.

111. Di Gennaro E, Bruzzese F, Pepe S, Leone A, Delrio P, Subbarayan PR, Avallone A and Budillon A: Modulation of thymidilate synthase and p53 expression by HDAC inhibitor vorinostat resulted in synergistic antitumor effect in combination with 5FU or raltitrexed. Cancer Biol Ther 8: 782-791, 2009.

112. Ouyang D, Zhang Y, Xu L, Li J, Zha Q and He X: Histone deacetylase inhibitor valproic acid sensitizes B16F10 melanoma cells to cucurbitacin B treatment. Acta Biochim Biophys Sin (Shanghai) 43: 487-495, 2011

113. Lee HI, McGregor RA, Choi MS, Seo KI, Jung UJ, Yeo J, Kim MJ and Lee MK: Low doses of curcumin protect alcoholinduced liver damage by modulation of the alcohol metabolic pathway, CYP2E1 and AMPK. Life Sci 93: 693-699, 2013

114. García-Niño WR and Pedraza-Chaverrí J: Protective effect of curcumin against heavy metals-induced liver damage. Food Chem Toxicol 69: 182-201, 2014.

115. Cerný D, Lekić N, Váňová K, Muchová L, Hořínek A Kmoníčková E, Zídek Z, Kameníková L and Farghali H: Hepatoprotective effect of curcumin in lipopolysaccharide/galactosamine model of liver injury in rats: Relationship to HO-1/CO antioxidant system. Fitoterapia 82: 786-791, 2011.

116. Aggarwal BB, Kumar A and Bharti AC: Anticancer potential of curcumin: Preclinical and clinical studies. Anticancer Res 23 (1A): 363-398, 2003.

117. Sun Y, Zhang J, Zhou J, Huang Z, Hu H, Qiao M, Zhao X and Chen D: Synergistic effect of cucurbitacin B in combination with curcumin via enhancing apoptosis induction and reversing multidrug resistance in human hepatoma cells. Eur J Pharmacol 768: 28-40, 2015.
118. Tannin-Spitz T, Bergman M and Grossman S: Cucurbitacin glucosides: Antioxidant and free-radical scavenging activities. Biochem Biophys Res Commun 364: 181-186, 2007.

119. Duangmano S, Sae-Lim P, Suksamrarn A, Patmasiriwat $P$ and Domann FE: Cucurbitacin $B$ causes increased radiation sensitivity of human breast cancer cells via G2/M cell cycle arrest. J Oncol 2012: 601682, 2012.

120. Smit HF, van den Berg AJJ, Kroes BH, Beukelman CJ, Quarles van Ufford HC, van Dijk H, Labadie RP and Labadie RP: Inhibition of T-lymphocyte proliferation by cucurbitacins from Picrorhiza scrophulariaeflora. J Nat Prod 63: 1300-1302, 2000.

121. Chen JC, Chiu MH, Nie RL, Cordell GA and Qiu SX: Cucurbitacins and cucurbitane glycosides: Structures and biological activities. Nat Prod Rep 22: 386-399, 2005.

122. Jayaprakasam B, Seeram NP and Nair MG: Anticancer and antiinflammatory activities of cucurbitacins from Cucurbita andreana. Cancer Lett 189: 11-16, 2003.

123. Miro M: Cucurbitacins and their pharmacological effects. Phytother Res 9: 159-168, 1995.

124. Xiao Y, Yang Z, Wu QQ, Jiang XH, Yuan Y, Chang W, Bian ZY, Zhu JX and Tang QZ: Cucurbitacin B: Cucurbitacin B protects against pressure overload induced cardiac hypertrophy. J Cell Biochem 118: 3899-3910, 2017.

125. Hua S, Liu X, Lv S and Wang Z: Protective effects of Cucurbitacin $B$ on acute lung injury induced by sepsis in rats. Med Sci Monit 23: 1355-1362, 2017.

126.El Naggar MB, Chalupová M, Pražanová G, Parák T, Švajdlenka E, Žemlička M and Suchý P: Hepatoprotective and proapoptotic effect of Ecballium elaterium on $\mathrm{CCl}_{4}$-induced hepatotoxicity in rats. Asian Pac J Trop Med 8: 526-531, 2015.

127. Li ZJ, Shin JM, Choi DK, Lim SK, Yoon TJ, Lee YH, Sohn KC, Im M, Lee Y, Seo YJ, et al: Inhibitory effect of cucurbitacin B on imiquimod-induced skin inflammation. Biochem Biophys Res Commun 459: 673-678, 2015.

128. Park SY, Kim YH and Park G: Cucurbitacins attenuate microglial activation and protect from neuroinflammatory injury through Nrf2/ARE activation and STAT/NF- $\kappa$ B inhibition. Neurosci Lett 609: 129-136, 2015.

129. Peters RR, Farias MR and Ribeiro-do-Valle RM: Antiinflammatory and analgesic effects of cucurbitacins from Wilbrandia ebracteata. Planta Med 63: 525-528, 1997.

130. Seo CR, Yang DK, Song NJ, Yun UJ, Gwon AR, Jo DG, Cho JY, Yoon K, Ahn JY, Nho CW, et al: Cucurbitacin B and cucurbitacin I suppress adipocyte differentiation through inhibition of STAT3 signaling. Food Chem Toxicol 64: 217-224, 2014.

131. Hassan STS, Berchova-Bimova K, Petras J and Hassan KTS: Cucurbitacin B interacts synergistically with antibiotics against Staphylococcus aureus clinical isolates and exhibits antiviral activity against HSV-1. S Afr J Bot 108: 90-94, 2017.

132. Duportets L, Maria A, Vitecek S, Gadenne C and Debernard S: Steroid hormone signaling is involved in the age-dependent behavioral response to sex pheromone in the adult male moth Agrotis ipsilon. Gen Comp Endocrinol 186: 58-66, 2013.

133. Mezher M: The essential list of regulatory authorities in Asia. Regulatory Affairs Professional Society, published April 4, 2015. http://www.raps.org/Regulatory-Focus/News/ Databases/2015/04/06/21908/The-Essential-List-of-RegulatoryAuthorities-in-Asia/. Accessed Sep 29, 2017.

134. David A and Vallance DK: Bitter principles of Cucurbitaceae. J Pharm Pharmacol 7: 295-296, 1955.

135. Baxter H, Harborne JB and Moss GP (eds): Phytochemical Dictionary: A Handbook of Bioactive Compounds from Plants. 2nd edition. Taylor \& Francis, Ltd., London, UK, p786, 1999.

136. World Health Organization: WHO Monograph on Selected Medicinal Plants. Volume 4: 266, 2009.

137. Ferguson JE, Fischer DC and Metcalf RL: A report of Cucurbitacin poisonings in humans. Rep Cucurbit Genet Coop 6: 73-74, 1983.

138. Therapeutic Goods Association: Health Safety Regulation Substances that may be used in listed medicines in Australia. Government of Australia, p86, 2011.

139. Le Men J, Buffard G, Provost J, Tiberghien R, Forgacs P, Lagrange E, Albert $\mathrm{O}$ and Aurousseau M: Relations entre la structure de quelques cucurbitacines, leur toxicité et leur activité laxative. Chim Therapeutique 4: 459-465, 1969 (In French).

140. Enslin PR: Bitter principles of the Cucurbitaceae. I. - observations on the chemistry of cucurbitacin A. J Sci Food Agric 5: $410-416,1954$

141. Gry J, Soborg I and Anderson HC: Identity, physical and chemical properties, analytical methods. Cucurbitacins in plant food. Ekspressen Tyrk \& Kopicenter, Copenhagen, Denmark, p18, 2006. 
142. Sezik E: Research on the Turkish medicinal plant Ecballium elaterium. Chem Nat Compd 33: 541-542, 1997.

143. Steyn DG: The toxicity of bitter-tasting cucurbitaceous vegetables (vegetable marrow, watermelons, etc.) for man. S Afr Med J 24: $713-715,1950$

144. Stoewsand GS, Jaworski A, Shannon S and Robinson RW: Toxicologic response in mice fed Cucurbita fruit. J Food Prot 48: 50-51, 1985.

145. Barri MES, Onsa TO, Elawad AA, Elsayed NY, Wasfi IA, Abdul-Bari EM and Adam SEI: Toxicity of five Sudanese plants to young ruminants. J Comp Pathol 93: 559-575, 1983.

146. Bakhiet AO and Adam SE: An estimation of Citrullus colocynthis toxicity for chicks. Vet Hum Toxicol 37: 356-358, 1995.

147. Rymal KS, Chambliss OL, Bond MD and Smith DA: Squash containing toxic Cucurbitacin compounds occurring in California and Alabama. J Food Prot 47: 270-271, 1984.

148.Pilegaard K and Søborg I: Squash med bitter smag. Nyt Levnedsmiddelstyrelsen Nr. 23: 1995 (In Danish).

149. Raikhlin-Eisenkraft B and Bentur Y: Ecbalium elaterium (squirting cucumber) - remedy or poison? J Toxicol Clin Toxicol 38: 305-308, 2000

150. Jung ME and Lui RM: Studies toward the total syntheses of cucurbitacins B and D. J Org Chem 75: 7146-7158, 2010.

151. Razavilar N and Choi P: Molecular dynamics study of the diffusivity of a hydrophobic drug Cucurbitacin $B$ in pseudopoly(ethylene oxide-b-caprolactone) micelle environments. Langmuir 30: 7798-7803, 2014.

152. Toker G, Memisoğlu M, Toker MC and Yesilada E: Callus formation and cucurbitacin B accumulation in Ecballium elaterium callus cultures. Fitoterapia 74: 618-623, 2003.
153. Mei J, Li S, Jin H, Tang L, Yi Y, Wang H and Ying G: A biotransformation process for the production of cucurbitacin B from its glycoside using a selected Streptomyces sp. Bioprocess Biosyst Eng 39: 1435-1440, 2016.

154. Lv Q, Shen C, Li X, Shen B, Yu C, Xu P, Xu H, Han J and Yuan H Mucoadhesive buccal films containing phospholipid-bile salts-mixed micelles as an effective carrier for cucurbitacin B delivery. Drug Deliv 22: 351-358, 2015.

155. Molavi O, Ma Z, Mahmud A, Alshamsan A, Samuel J, Lai R, Kwon GS and Lavasanifar A: Polymeric micelles for the solubilization and delivery of STAT3 inhibitor cucurbitacins in solid tumors. Int J Pharm 347: 118-127, 2008.

156. Patel SK, Lavasanifar A and Choi P: Roles of nonpolar and polar intermolecular interactions in the improvement of the drug loading capacity of PEO-b-PCL with increasing PCL content for two hydrophobic Cucurbitacin drugs. Biomacromolecules 10: 2584-2591, 2009.

157. Cheng L, Xu PH, Shen BD, Shen G, Li JJ, Qiu L, Liu CY, Yuan HL and Han J: Improve bile duct-targeted drug delivery and therapeutic efficacy for cholangiocarcinoma by cucurbitacin B loaded phospholipid complex modified with berberine hydrochloride. Int J Pharm 489: 148-157, 2015.

158. Wang W, Zhao X, Hu H, Chen D, Gu J, Deng Y and Sun J: Galactosylated solid lipid nanoparticles with cucurbitacin B improves the liver targetability. Drug Deliv 17: 114-122, 2010.

159. You L, Wang Z, Li H, Shou J, Jing Z, Xie J, Sui X, Pan H and Han W: The role of STAT3 in autophagy. Autophagy 11: 729-739, 2015. 